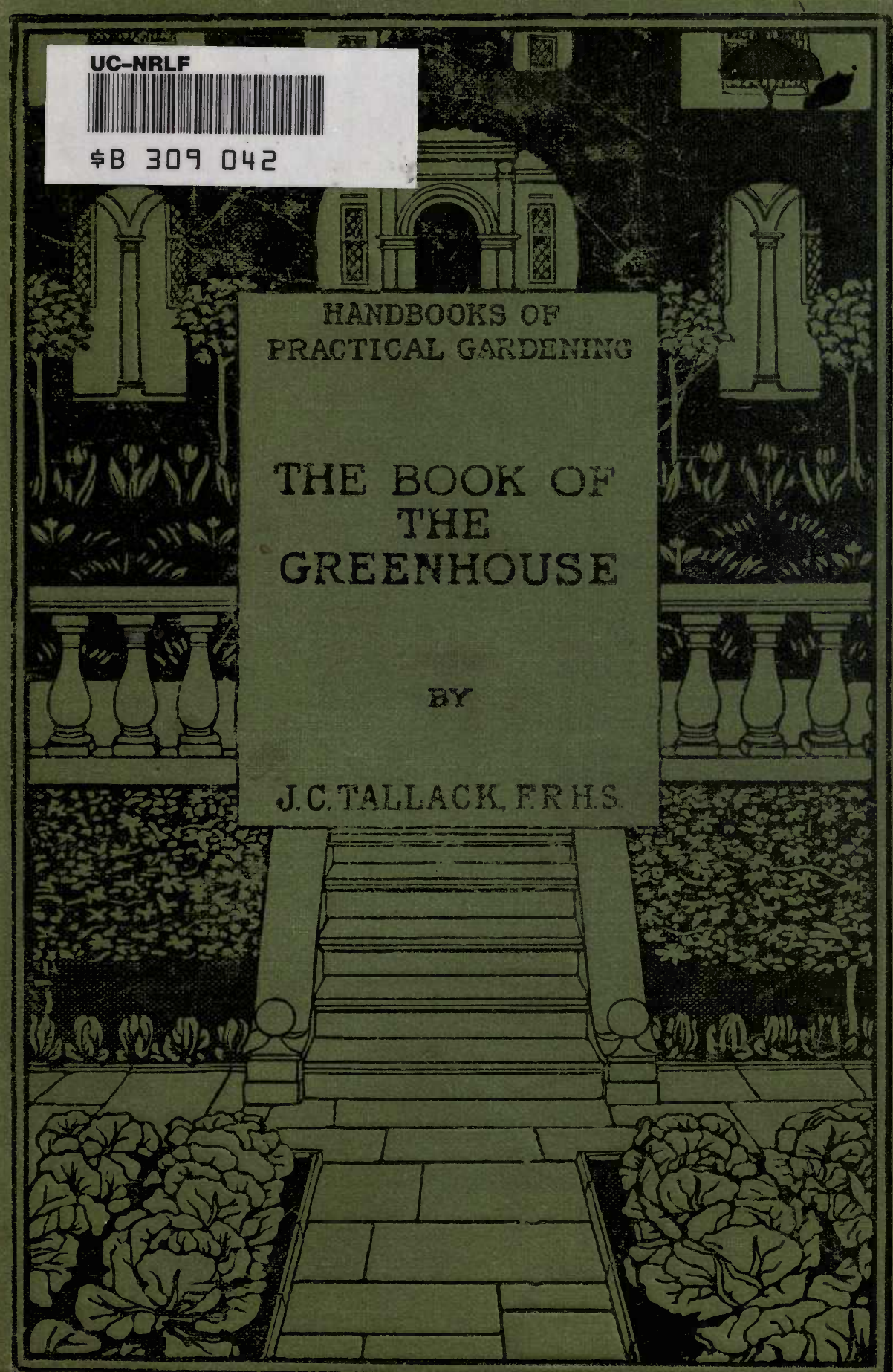




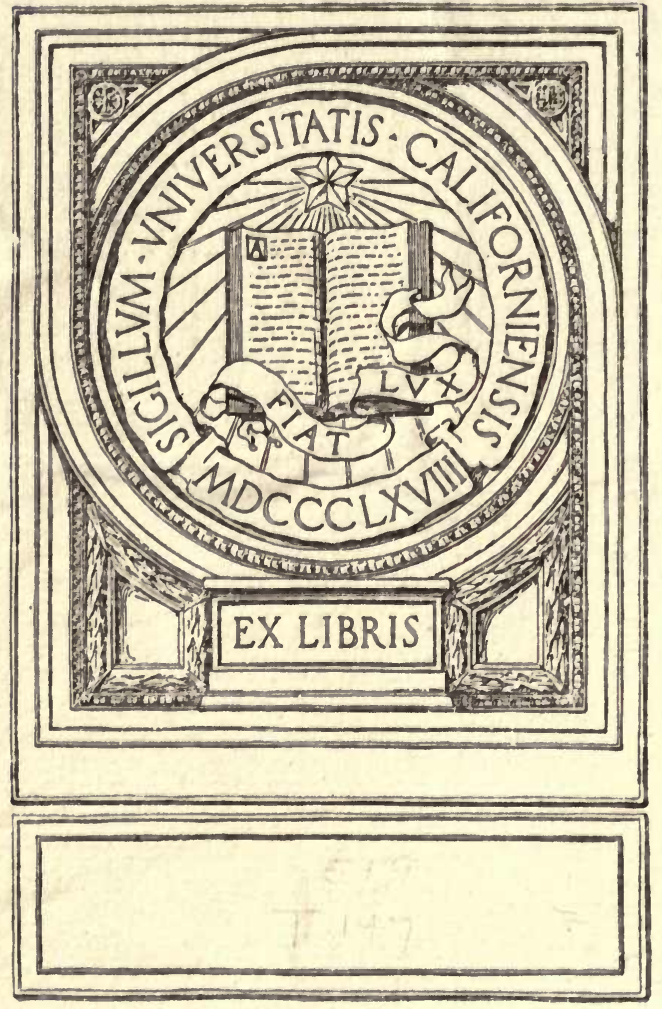




HANDBOOKS OF PRACTICAL GARDENING EDITED BY HARRY ROBERTS

THE BOOK OF THE GREENHOUSE 


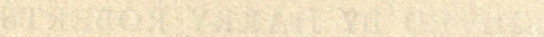




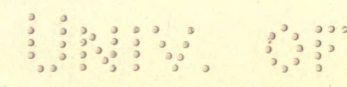

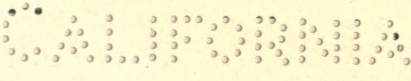




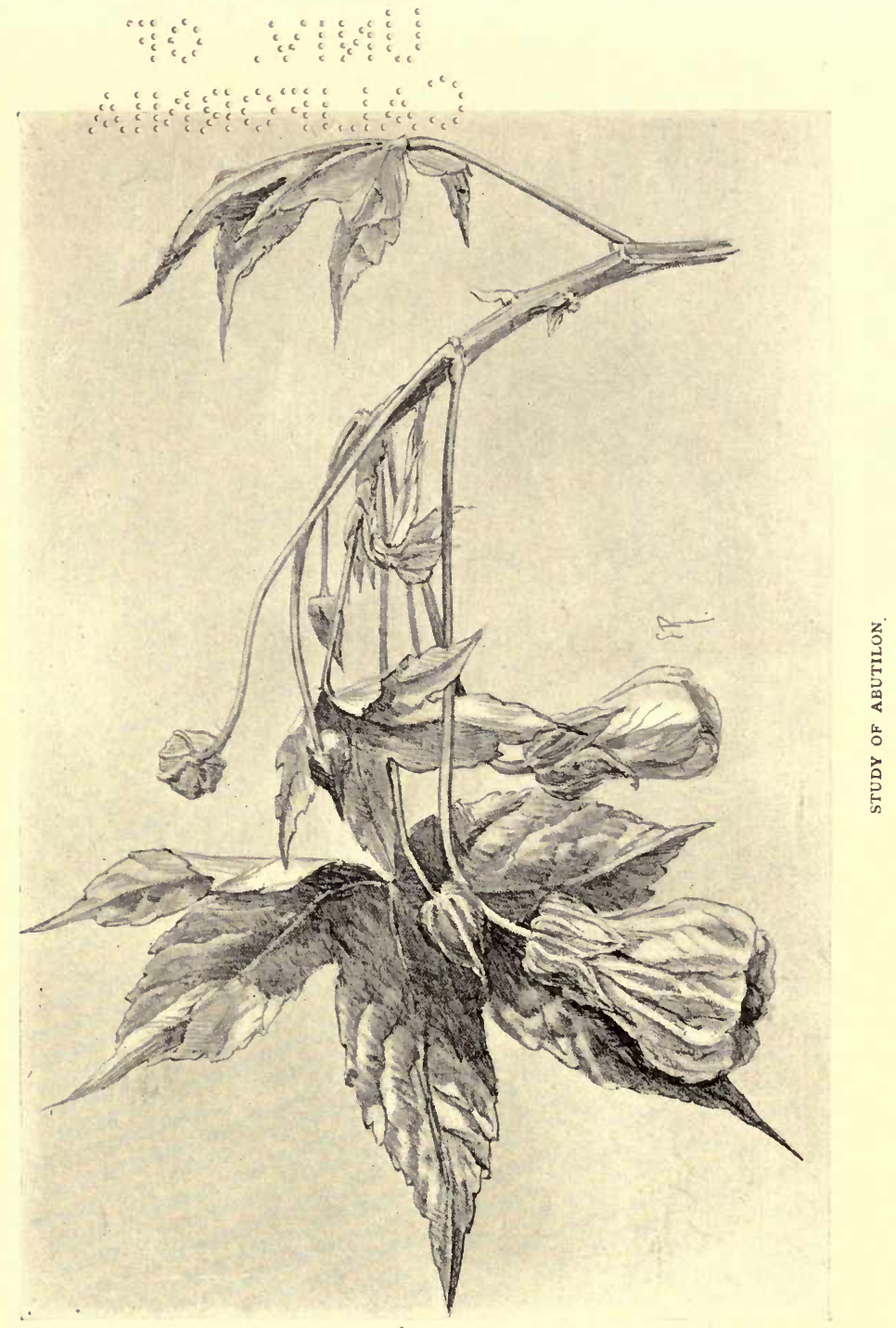




\section{THE BOOK OF \\ THE GREENHOUSE}

WITH A SPECIAL CHAPTER ON

THE LITTLE TOWN GREENHOUSE

\section{J. C. TALLACK, F.R.H.S. \\ HFAD GARDENIR AT SHIPLET HALL.}
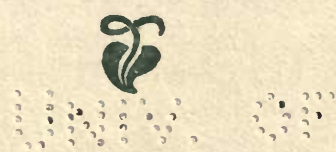

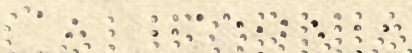

LONDON: JOHN LANE, THE BODLEY HEAD NEW YORK: JOHN LANE COMPANY. MCMVIII 
Second Edition

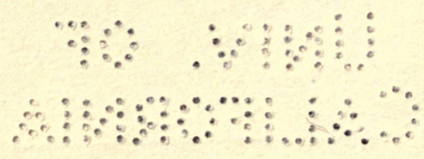

Printed by Turnbull \& Spears, Edinburgh 


\section{EDITOR'S NOTE}

THis book, like the other books in the present series, is the work of a practical gardener, $\mathrm{Mr}$ Tallack having been engaged in horticultural work during most of his adult life. Born a Cornishman, he served his apprenticeship in the once celebrated gardens of Canon Philpotts, of Porthquidden, where the glass department was a feature. Having gained further experience at Wymyard Park, Durham, Luton Hoo Park, Bedfordshire, and elsewhere, he obtained his first head-gardenership at Prideaux Place, Padstow, where he effected many improvements. Having meanwhile been engaged for two years in landscape-work with Messrs. Veitch, he then for twelve years took charge of the gardens at Livermere Park, Suffolk. He is now in command of the well known midland garden at Shipley Hall, Derby, in which the glass houses are many and important.

For some years $\mathrm{Mr}$ Tallack lectured on Horticulture under the Suffolk County Council, and he has been a regular contributor to The Garden and other gardening papers for the past twenty years. $\mathrm{He}$ is an enthusiastic gardener, and has been awarded the Knightian and Banksian medals of the Royal Horticultural Society.

The Editor acknowledges with thanks the courtesy of Messrs. Veitch, the distinguished florists of the Royal Exotic Nursery, Chelsea, in permitting the illustration of their plants, Maranta Major and Dracaena, the Sirdar; and also the kindness of Messrs Messenger, the well known horticultural builders of Loughborough, for permission to illustrate some of their structural work. 



\section{CONTENTS}

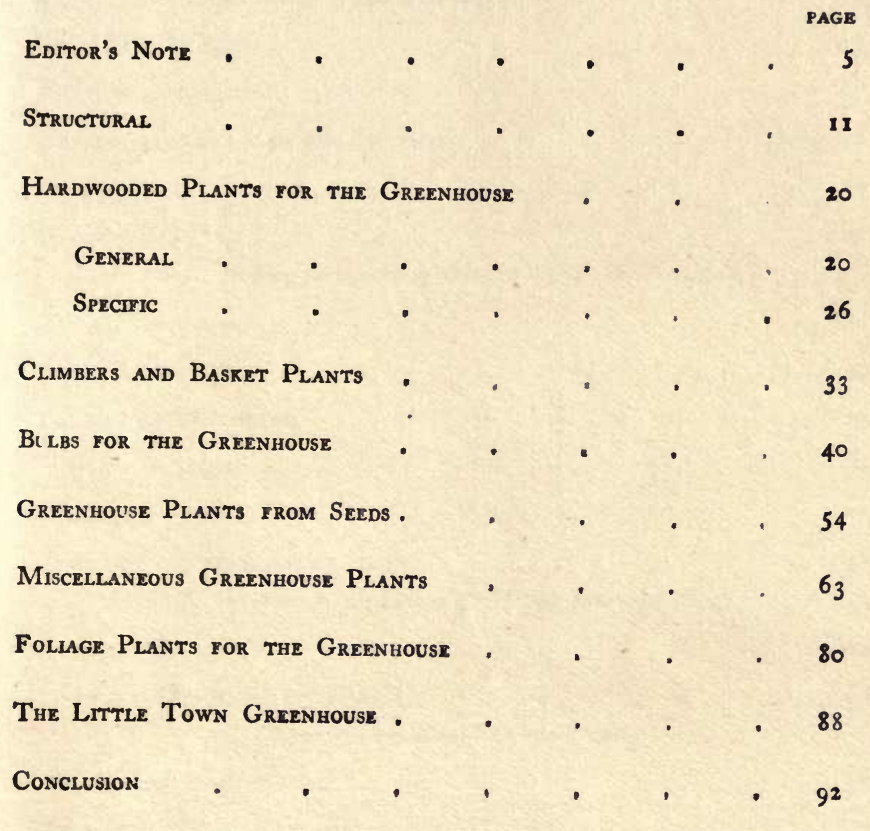





\section{ILLUSTRATIONS}

Studr or AButilon (from a drawing by Ethel Roskruge) Frontispiece Ventilation by means of Framed Lights a $\quad$ - 12

Lead Bar Glazing • • • • • • 15

Heating Apparatus •

Azalea, Madame Van der Cruyssen . - bacing 22

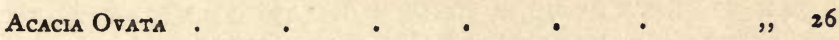

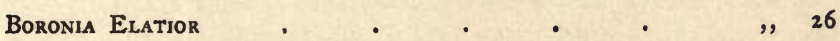

(Reproduced by permission of Messrs Veitch $๒$ Sons, Ltd.)

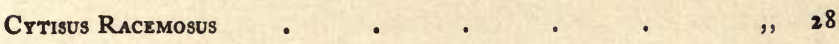

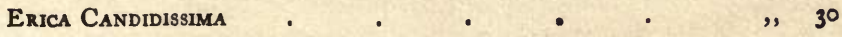

Eriostemon Nerifolius . $\quad$ - $\quad$ o 42

Deutzla Gracilis $\quad$ • $\quad$ • $\quad$ • $\quad$ " 52

Cineraria Hrbrida • . • . . " 56

Campanula Pyramidalis Alba. . . .

(Reproduced by permission of Messrs Sutton $v$ Sons)

Crclamen Persicum

Sutton's White Star Primula.

(Copyright by Messrs Sutton $\xi$ Sons)

Hydrangea Hortensis . . . . . " 72

Dracaena, The Sirdar . $\quad$ - $\quad$ - $\quad$ - 80

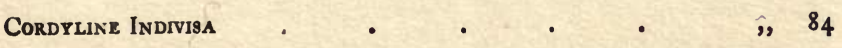

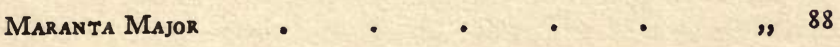




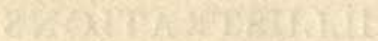

$3=5 x=$

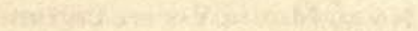




\title{
THE BOOK OF THE GREENHOUSE
}

\section{CHAPTER I}

\author{
STRUCTURAL
}

No garden can be considered complete or satisfying to its possessor, unless it contain a greenhouse in which may be cultivated beautiful flowers and plants that are impossible in this country without the aid of glass and protection. To the plant lover, one or more of such structures will, if well placed, well fitted, and, especially, well filled, be an endless source of pleasure, and peculiarly so during the dreary period of the year when plant life is more or less dormant in the outside garden. Probably most of my readers already possess a greenhouse, but it is to those who contemplate adding such a building to their possessions that this opening chapter is directed, with a hope that the hints which it contains, though necessarily in few words, will be helpful.

The site for a greenhouse should be selected with care, bearing in mind that it must be well exposed to day-light and, if possible, well sheltered from easterly and northerly winds. As a sunk furnace is easier in working and less wasteful of fuel than one set on the level, the house should stand on fairly high and well drained ground, so that there may be no trouble from surface water. No trees should overhang or even be allowed near enough to the house to shade it at any time of day.

Span-roofed houses, i.e. those with two equal sides to the roof, should always be built with the ends facing 


\section{i2 THE BOOK OF THE GREENHOUSE}

north and south, and if one end is formed by an already existing wall this should be the north end. Such houses

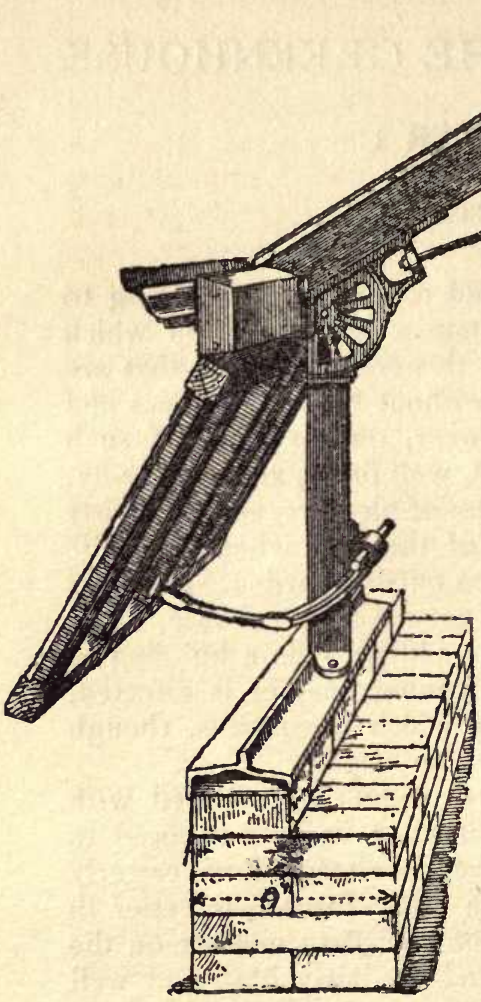

VENTILATION BY MEANS OF FRAMED LIGHTS

are more easily managed, and their occupantsalways happier than is the case with houses built from east to west. A span-roofed house, built sufficiently wide to permit of a central stage in addition to two narrow side stages, is perhaps the very best possible form of house, as its occupants can always be arranged so that they may be seen at their best, but, where the width is only sufficient to admit of two side stages with a path down the centre, I consider the span a wasteful form of house and one in which plants can never be arranged to look well, as, unless the house is lofty, the tallest plants are perforce brought next the eye and the others graded away from, instead of towards, the path.

Lean-to houses are those in which the roof takes one slope only from back to front. For a position against a wall this is the cheapest and perhaps the best form of 
greenhouse. It may be built with any aspect from south to west, and for certain purposes, such as the cultivation of Ferns, a house of this form facing north is most useful. The worst aspect of all is towards the east.

The internal arrangements should consist of a narrow front stage, then the path, leaving the biggest space for the back stage. This latter may be built in tiers like a series of steps if the height of the roof permit, and will then present more staging room as well as bring the back plants nearer the roof-an important matter in plant-growing under glass.

The Hip-Span is a useful form of house for building against a wall too low to suit a lean-to. It is a combination of the span and the lean-to, the short "hip" or span at the back adding height and forming a convenient position for the ventilators. The above forms of houses are those most in use, and any departure from or combination of them is only carried out for the sake of ornament.

Next in importance to the building itself comes the ventilation of the house. Elaborate ventilating arrangements are by no means necessary, but provision must be made for an ample supply of fresh air when it is needed. By an ample supply I do not mean that there is need for many different sets of ventilators, for these often lead to draughts which are inimical to plant life and breeders of mildew. Ample means of admitting air must be given at the apex of the roof, and these roofventilators must be continuous throughout the whole length. Those houses which have some of the rooflights fixed and others made to open are sure breeders of insect pests, besides endangering the plants beneath such fixed lights by scorching. Too much importance cannot be placed on the value of ample top ventilation, as the air may thus be entirely changed without creating 


\section{THE BOOK OF THE GREENHOUSE}

draught. In comparison with the top ventilators, those at the sides or bottom of the house are quite unimportant; indeed, many of the best plant growers of the present day never use side ventilation at any time, reckoning it not only useless but harmful for many plants, as it dissipates too readily the natural humidity created in a houseful of plants, and which the great majority of plants enjoy. Some plants, however, prefer a dry atmosphere, and for these side ventilation should be arranged and used cautiously: a few small sliding shutters placed low down, so that the fresh air may feel the influence of the hot water pipes in cold weather, will suit the requirements admirably.

We will now consider the question of the stages or benches to be used. This is not the unimportant matter that it is often considered to be. I attribute many of the failures and the successes largely to the staging arrangements of the house. The most common method of staging plants is to put them on benches formed of narrow strips of wood placed an inch or two apart, thus having an open space between them. This I consider to be quite the worst form of staging, and more especially so where the hot water pipes are placed immediately beneath such stages, for the fire heat necessary in very cold weather does much harm to the root action by over drying the pots, and thus killing the tips of tender rootlets. Undoubtedly the best of stages are formed by good thick slates, as these are always cool and slightly absorbent, so that the bottoms of pots standing on them never become really dry; but slates are expensive to begin with, and wood does nearly as well provided that the boards are placed close enough together to support a surfacing of shingle, ashes, or some other covering of an absorbent nature. A narrow strip can be nailed round these wood benches to retain the inch or so of this material. All stages placed over hot water pipes 
should be carried quite back to the wall on the one side and project well beyond the pipes on the side next the walk, for heat striking directly on to plants from the pipes is the cause of much mischief.

For propagating purposes, I would suggest that where only one greenhouse is possible it should always contain

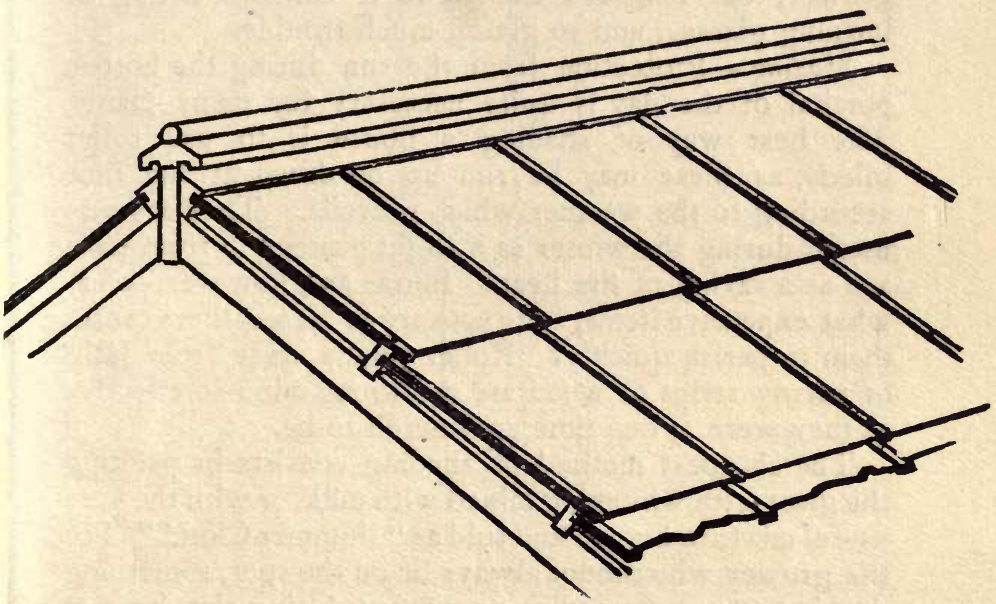

LEAD BAR GLAZING

a propagating box of some kind. This should be fixed at a convenient point where it may enclose some portions of the hot water pipes, which may then be buried in a good depth of cocoanut fibre. This box may be a fixture, or may be movable, so that it will only be in the house when needed, but it will be found a most useful adjunct, and will provide means for raising young plants of all descriptions either from seeds or from cuttings. 


\section{I6 THE BOOK OF THE GREENHOUSE}

Glazing.-I do not propose to enter into much detail as to this. Personally, I prefer the system of glazing without outside putty, as it appears to be the most drip proof system when the houses are well looked after as regards painting. One special point must be emphasised as regards glazing. This is to use only the best twentyone ounce glass. Inferior glass is a misery to the plant grower, the bladders and flaws it contains acting as burning glasses, and so giving much trouble.

Shading.-Protection from the sun during the hottest portion of the day is quite necessary for many plants. The best way of shading a house is to use roller blinds, as these may be run up or down at any time according to the weather which prevails. They are also useful during the winter as a slight protection from frost and as a saving of fire heat. Blinds are, however, somewhat expensive items, for exposure to all weathers causes them to perish quickly. Roller blinds made from laths or narrow strips of wood are not to my mind so effective as they were at one time considered to be.

The cheapest method of shading consists in painting the glass with whitening mixed with milk, or with the very useful mixture known and sold as " Summer Cloud." For the grower who cannot always be on the spot, something that is to a certain extent permanent during the summer months is necessary, and these washes provide a cheap and effective shade. The objection to them is that they are on in dull as well as in fine weather, but this is counterbalanced by the fact that they are always on the spot when needed, and this cannot always be said of movable blinds however careful one may be.

Heating.- The heating of greenhouses has gone through many phases during the past half century, but I think that at last we may claim to have a really good system in the use of hot water for the purpose. It is a matter for rongratulation that the old system of using hot air flues 


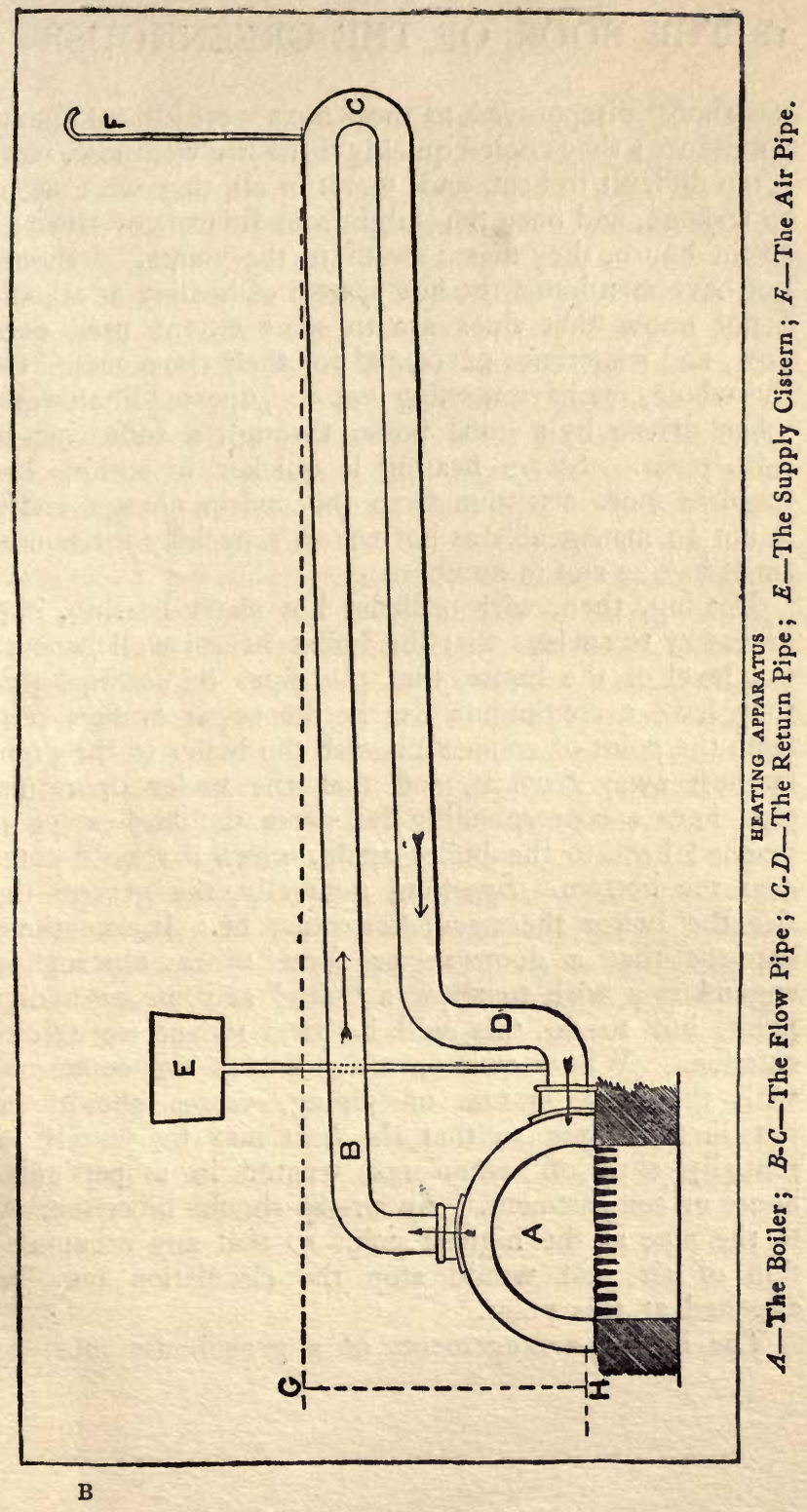




\section{THE BOOK OF THE GREENHOUSE}

has almost disappeared, as these flues were almost always a nuisance; they cooled quickly if the fire went low, were often difficult to heat, and, worst of all, they were prone to leakage, and once the sulphurous fumes got through to the house, they meant death to the plants. I should not have mentioned the flue system of heating at all, did I not know that flues are to some extent used even now, and sometimes advocated for their cheapness. On the whole, we have nothing yet to supersede hot water when driven by a good boiler through a sufficiency of 4-in. pipes. Steam heating is quicker in action, but requires more attention from the one in charge, and it is not so manageable as hot water, especially for houses small in size and in number.

Dealing, then, with ordinary hot water heating, it is necessary to success that the boiler be set well beneath the level of the house, that the pipes be so fixed that they have a continuous rise in the upper or flow pipe from the point of connection with the boiler to the point farthest away from it, and that the under or return pipe have a corresponding fall from the highest point reached back to the boiler again, which it should enter near the bottom. Speaking generally, the greater the rise the better the circulation must be. It sometimes happens that a doorway or some other obstruction engenders a wish to allow a "dip" at some particular point, but to do this will be fatal to successful circulation. Where two or more houses are connected with the same system of piping, valves should be put in the pipes so that the heat may be wholly or partially shut off when not wanted in a particular house or compartment. An air-tap should be connected to the pipe at the highest point so that any accumulation of air that would stop the circulation may be expelled at this point.

The heating arrangements of a greenhouse must of 
course be governed to some extent by the class of plant it is to contain. Cool house plants, and even so-called hardy plants, when grown in pots, must have some fire heat in winter. For such things two rows of 4 -in. piping running lengthwise and across one end of the house would be sufficient. For the warmer greenhouse four rows of 4-in. piping traversing the same distance would be necessary. An approximate estimate is that I foot of 4-in. piping will heat moderately 30 cubic feet of space, but it should be borne in mind that it is far better to have too much than too little piping, as the heat given off to keep up a given temperature will be less fiery and injurious in proportion to the additional piping used. In choosing the boiler do not be misled into getting one that is too small for its work. Allow a broad margin beyond the maker's estimate of size necessary to heat a given quantity of piping. A new boiler well fixed and driven hard by constant attention may do all that is claimed for it at first, but will not continue to do so for long without more attention than one is prepared to give it. In any case, the amount of necessary attention is less with a fairly big boiler than it is with a small one.

The Garden Frame.-An indispensable companion to the greenhouse is the portable garden frame. Under good management it will never be empty for long together, and will act as a feeder to the greenhouse proper, for in it can be raised and "grown on" plants innumerable, which will in their turn help to embellish the more pretentious structure. Its several uses will be mentioned as I deal with the cultivation of plants in other chapters, and this must serve as an apology for so briefly dismissing it in this. 


\section{CHAPTER II}

Hard-Wooded Plants for the Greenhouse

As a preface to the cultural portion of this little treatise I should like to say that it will be impossible to deal in a satisfactory way, in the space at my disposal, with all or even with a large portion of true greenhouse plants, as the result of so doing would be to compile something scarcely better than a catalogue, and of little, if any, value to the reader. I propose, therefore, to deal in a general way with the management of the various sections, each section as a unit, and to particularise only in the case of plants which are fairly common in cultivation and such as the great majority of plant lovers would wish to grow. I regret that many charming species will thus be left unmentioned and must be sought for in works of greater pretension.

Hard-wooded plants, so called, are mostly of bush shape and shrubby habit, though many climbers are also included in this section. Familiar examples of plants comprised under this heading are Azaleas, Ericas (Heaths), Camellias, Cytisus (Genistas), Epacris, Boronias and Daphnes. A few years ago one would have included many more as familiar plants, but unfortunately the easy culture of the many soft-wooded plants has led to the discarding of plants more beautiful, when seen at their best, than many of the favourites of to-day.

Hard-wooded plants as just implied are as a class a little difficult to grow well; for, though some few of 20 
them will bear a certain amount of rough treatment and neglect, they can only be well grown when all their wants are carefully attended to. The majority have small hair-like roots which, though numerous, have no great capacity for storing moisture, hence some of the difficulties of their culture for, if over-watered, the roots cannot assimilate the surplus quickly and the soil under its influence turns sour, while, on the other hand, if allowed to become dry, the tiny tips of the roots wither and are not easily or quickly replaced-indeed, plants of some species never recover from the effects of being allowed to get thoroughly dry. Most of the plants in this section like a peaty soil, the majority succeeding well in a mixture of two-thirds fibrous peat, one-third fibrous loam and sufficient silver sand to make the mixture feel thoroughly gritty when handled. It is not necessary to repot every year, indeed with care in management several years may elapse between the pottings, but when it has to be done, either through a noticeable want of vigour in the older plants or from a desire to grow younger ones on into fine specimens as soon as may be, special care is needed in carrying out the work in all details. Clean pots must be used; if the insides be left dirty the new roots will stick fast and be wrenched off at the next potting. The new pots should not greatly exceed in size those from which the plants are to be transferred. No new pot should be used until it has been soaked in water for a few hours and allowed to get dry again.

Drainage should be thorough : this does not imply an excessive use of crocks, but rather that those used should be well placed in the pots and covered with a little of the toughest fibre that can be selected from the soil heap and freed from all fine particles. Previously to being turned out of the old pot, the plant to be operated on should be watered just long enough to 
allow of the soil being in that nice condition known as neither wet nor dry, and the new soil should be in about the same condition, i.e., damp enough to bind together when rammed, yet not so wet as to become pasty with ramming. Sufficient new soil should be put into the new pot to elevate the ball of soil and roots attached to the plant, which has been previously freed from the old drainage material, high enough to prevent any portion of the stem which has hitherto been uncovered from becoming buried in the process of potting, as to bury the "collars" of these plants is generally injurious and often fatal to them. Some of the more delicate species, indeed, do better and live longer when the "collar" is left slightly higher than the surrounding soil. To complete the potting in a workmanlike way the old ball of soil should be placed exactly centrally, so that there may be an equal distribution of new soil all round it, and this should be put in a little at a time, each successive layer being well rammed home, leaving no crevices, until the potting is complete. Potting should take place at a time when the roots have resumed activity after a slight rest. This will in most cases be when the new growth, made after flowering, has been perceptible for two or three weeks. As the period of growth varies according to the different species and their time of flowering, no particular period can be mentioned, except that it is some time during spring or early summer.

Most of the plants in this section are essentially what are known as cool greenhouse plants and are very impatient of fire heat at any time. This, combined with their inability to withstand frost, renders their cultivation a matter of careful watching and solicitude on the part of the grower. In the winter, the temperature of the house may safely be allowed to fall within a very few degrees of freezing point, when the outside tempera- 
$\vdots, \ldots \ldots$

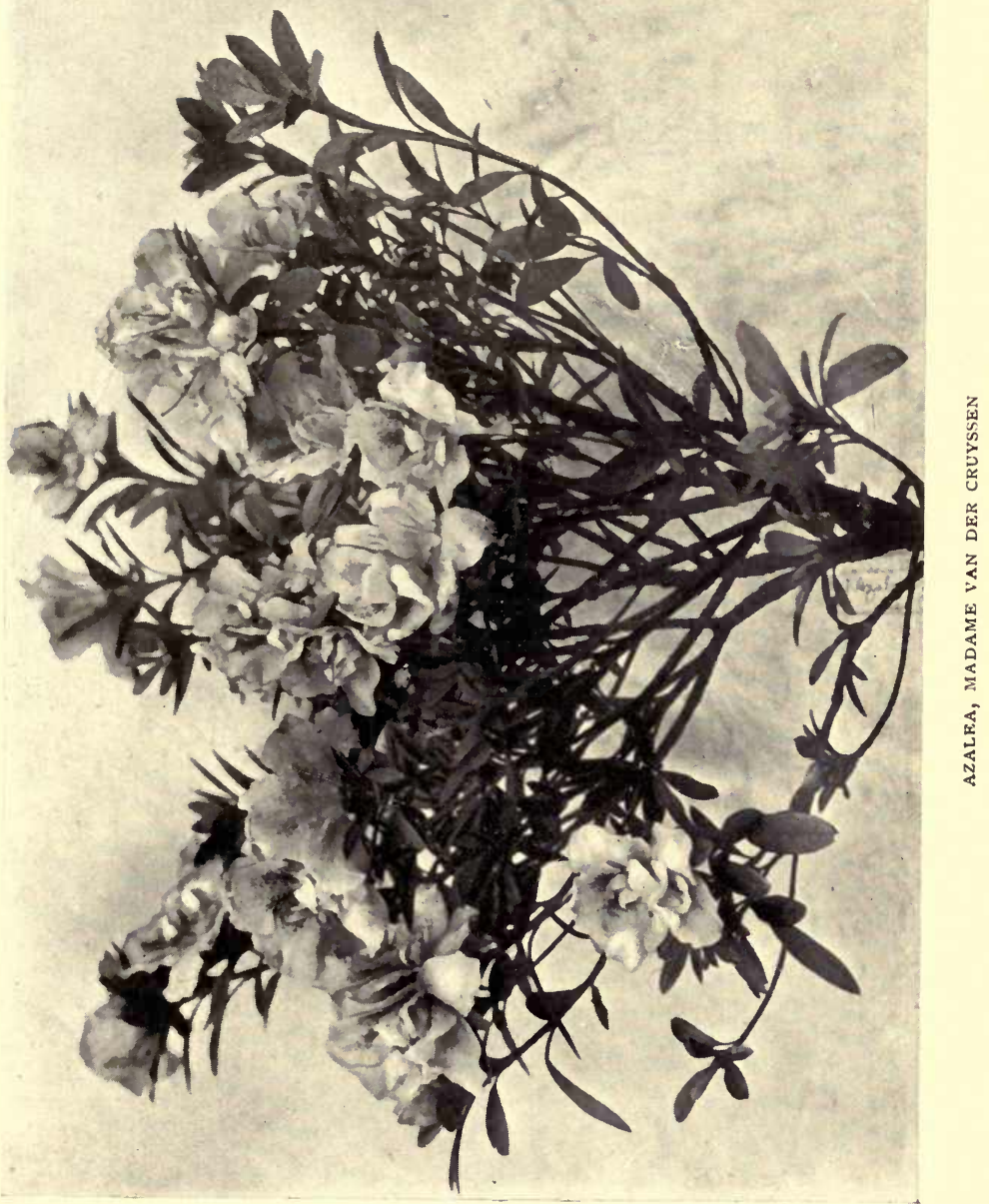


ture is very low; this will be far better than firing up to maintain the $45^{\circ}$ which is considered to be the regulation minimum temperature in normal weather. At all times there should be ventilation, and even in frosty weather some air should be admitted through the top ventilators, indeed, when the weather is mild, full ventilation from all points, short of creating great draught, ought to be provided, the only time when one can permit oneself a little license in the way of keeping the plants somewhat closer than usual being just for a week or two after they are potted, to encourage root growth. It must always be remembered that the new annual growth must be given full opportunity of becoming well ripened before winter, and this cannot happen in a close atmosphere. During the brightest weather of the spring and summer months, a light shade may be necessary; but full advantage of the autumn sunlight should be taken to ripen up the newly made growth. In some cases it is an advantage to put the plants in the open air during autumn, plunging the pots in ashes to prevent the roots from parching, and to leave them out while the weather remains fine and mild; but they must on no account be left out in continuous rain.

With regard to watering, sufficient has been already said as to the care which should always govern operations. Plants must not be allowed to be dry for long together, neither must they be watered before they have reached that stage of dryness at which water is needed. No exact rule can be laid down to indicate when a plant should be watered, and experience is the only safe guide to the requirements in this way; the gaining of this experience being the one great stumbling block which stands in the way of the would-be grower of hard-wooded plants. A fairly safe test is, however, the old fashioned one of tapping each pot with the 


\section{THE BOOK OF THE GREENHOUSE}

knuckles. If the result is but a dull response, such as one would get from tapping any solid body, no water is required; but if a hollow or slightly ringing sound be produced, then the time for watering has come. Should the ringing be accentuated, the plant should be plunged in a pail of water and left there for a few minutes to absorb as much as it can and to allow the water to reach the middle of the ball, dryness of which is not easily remedied by giving water in the usual way through the spout of a watering-pot. The avoidance of such excessive dryness as this, however, should be one of the chief cares with the grower, as fatal results of such neglect are to be expected.

Many hard-wooded plants being averse to lime in any form, provision should always be made for a supply of soft water, and if this is not sufficient for all the plants grown in the greenhouse it should be specially reserved for those of this class.

Overhead syringing is not often necessary, though for a time, during the early period of new growth, a dewing of soft water appears beneficial, and the plants certainly seem to thrive under the influence of the heavy night dews which they experience during fine weather when growing in the open air.

Insect pests do not as a rule give much trouble to hard-wooded plants which are well looked after and well treated, but there are some which trouble certain plants, as for instance: Thrips are partial to Azaleas, Scale in variety to Camellias, White Scale to Neriums (Oleanders), Red Spider to Pimelias, and some of these plants have a common enemy in them all. Needless to say, the plants cannot thrive under attacks from these pests which sap their life blood and choke their pores with filth. In the matter of dealing with insect pests, however, the present day grower lives in comparative joy, for science during the past few years has produced many insecticides 
that enable us to cope with the enemies to plant life by safer and more effective methods than any that were formerly in vogue, and there is now but little excuse for dirty and insect-ridden plants.

When ventilation has been insufficient and the outer atmosphere foggy, Mildew becomes a great enemy to many hard-wooded plants, notably to Heaths, and as it is very insidious in its attacks it should be carefully looked for. A speck or two of decay among the tiny leaves of Heaths, or a white mould on larger leaved things will, if unchecked, soon develop alarming proportions. Directly such signs are seen, the plants, and especially the affected parts, should be dusted freely with Flowers of Sulphur, which is an effective antidote to Mildews. A sulphur duster or puff should always be at hand in the greenhouse, and its use never put off when required.

Hard-wooded plants are but rarely propagated in private places. Nurserymen have greater conveniences for this work and can carry it out in bulk, so that each batch of cuttings or seedlings may get exactly what is needed at all times. As this is not possible in a private place and as the process of raising these plants is a slow one in any case, it is always best to commence by buying established plants of fair size which will give a quick return in the way of flowers. Buying them when in flower is not, however, the best way. They should be bought long enough before flowering to get acclimatised in their new home. 


\section{CHAPTER III}

\section{Hard-Wooded Plants for the Greenhouse- continued}

TURNING now from generalities that may be applied to most plants in this section, I propose to give as fully as may be the details of treatment suited to each genus among those selected as being the most popular and most useful, and will begin with the

Acacias.-Though most of these develop into trees or big bushes in their native habitat, a few are amenable to pot culture, and can be maintained in a small state as free-flowering bushes. They are easily cultivated, and flower mostly in spring, when their innumerable tiny yellow balls are greatly appreciated. Those of which I give the names below may be well grown in small pots, and are therefore the most serviceable. The simple details of culture consist in giving cool greenhouse treatment in winter, allowing during that period a rather limited supply of water, pruning the plant into shape after flowering, potting if necessary soon after new growth begins, and putting them out of doors in a sunny spot during summer, throughout which period the supply of water must be ample. The soil for Acacias should be two-thirds loam, one-third leaf mould, and plenty of sand.- $A$. armata, of which bushy little plants profusely flowered and sweetly scented may be grown in 6-in. pots. A. lineata, $A$. Drummondii and $A$. ovata are all good.

Azaleas.-In these we have a genus of plants which, 


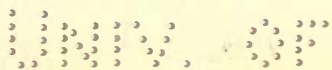

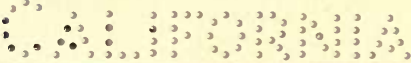

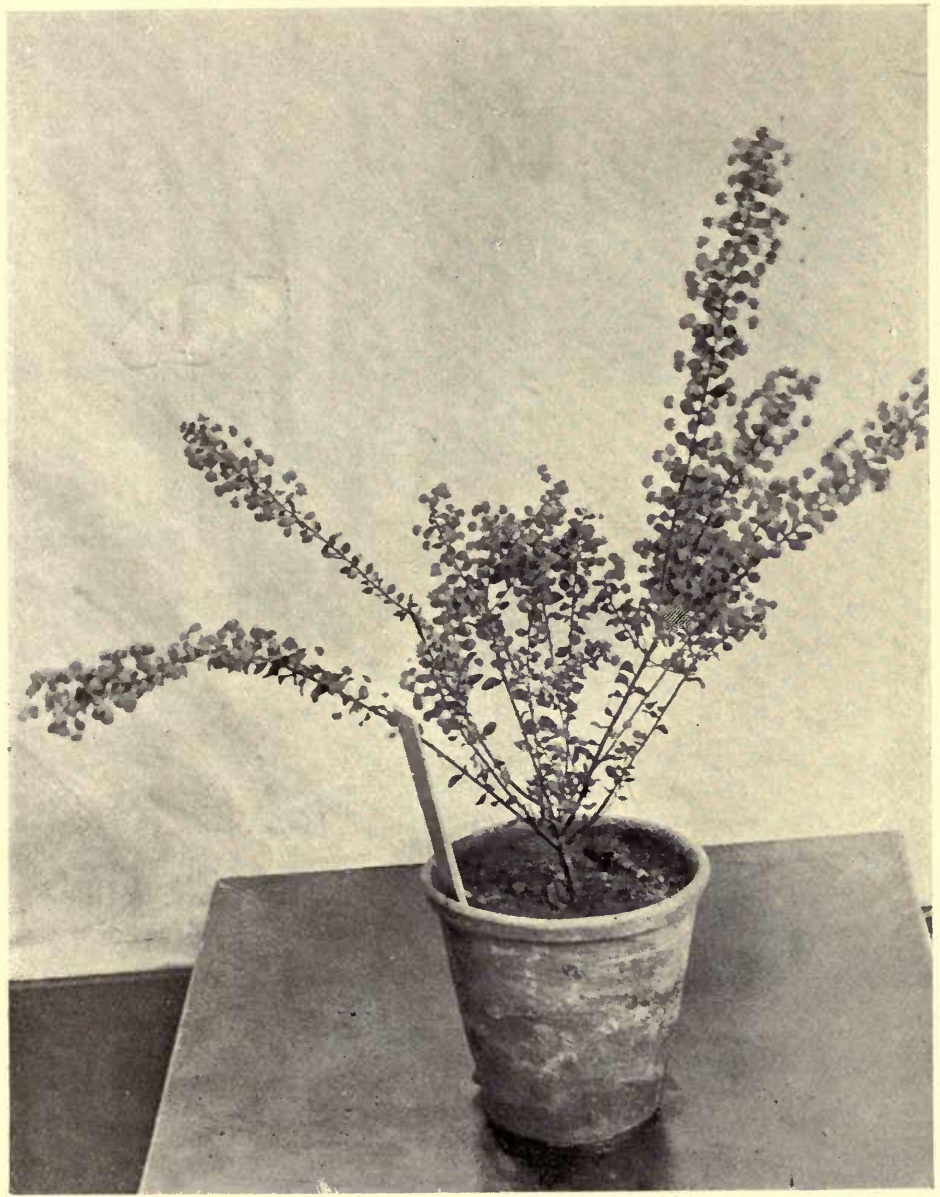

ACACIA OVATA 
at

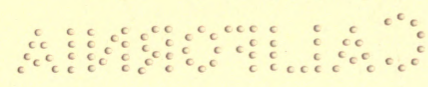




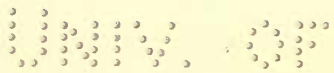

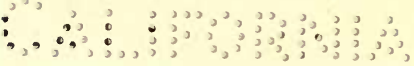

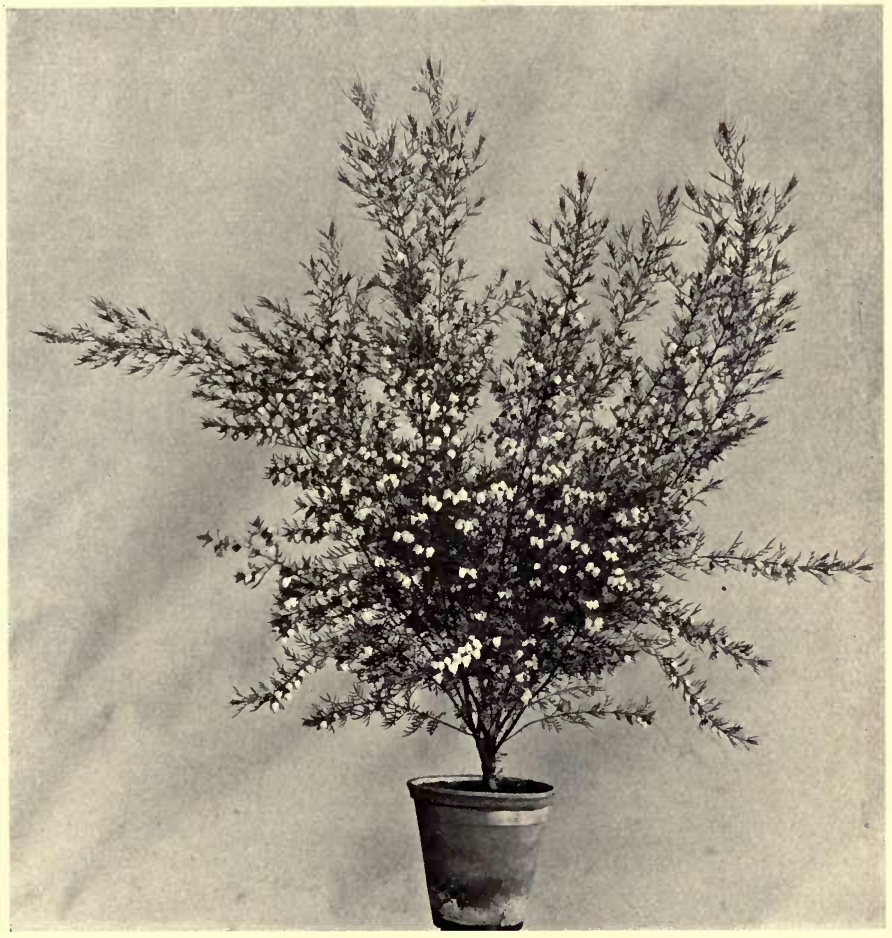

BORONIA ELATIOR

Reproduced by permission of Messrs. Veitch \& Sons, Ltd. 
का ankmentun 
taken as a whole, is more valuable than any other in the greenhouse. The Indian or Chinese section is the one to which the name of "greenhouse Azaleas" applies most fully, but the Ghent and Mollis types, the little A. amona, which has proved so valuable for hybridising purposes, and the double flowered $A$. balsamaflora all have their special value, and must not be omitted. The culture is similar to that laid down in chap. ii. for general guidance, but the Azalea will stand some artificial heat during the period of making growth; the Ghent, Mollis and Amœna varieties will bear considerable forcing, and provide a blaze of colour during the late winter and spring months. During the warmer parts of the year, the plants delight in being syringed daily. The best time for potting is soon after flowering, but many of these plants are allowed to go for years without potting, and still keep in good health. With the Indian section no pruning is necessary beyond the shortening of a strong growth which promises to destroy the balance of the plant and the removal of very weak shoots. This should be done directly the plants have flowered, and at the same time all old flowers and seed pods should be picked off. Small plants may be put into the garden frame during summer, and the larger ones may be stood out for a few weeks during the early autumn, and brought in again on the approach of frosty nights.

Boronias.-Though not showy as to their flowers, Boronias are greatly appreciated in the greenhouse from the exquisite perfume they emit during the flowering period which lasts over several weeks, one plant being sufficient to fill a large house with its fragrance. The general treatment advised will be found satisfactory, but to it must be added an extra caution with respect to watering, as the plant is quite impatient of an excess, and for this reason it should always be grown under cover, so that heavy rains may not reach it. 


\section{THE BOOK OF THE GREENHOUSE}

Camellias.-The stately if somewhat formal looking Camellia is known to all, and when well grown it makes one of the handsomest shrubs in existence. Its proper place is planted out in the border of a greenhouse or conservatory, but it may also be well grown in pots. As its roots are stouter than those of most hard-wooded plants it requires rather different treatment. At no time does it like to be dry, and plants well set with buds will take a lot of water, varied occasionally with liquid manure, during the time they are swelling. Plants allowed to get dry at the root often drop their buds. During spring and summer they like shade enough to prevent the leaves from scalding. Potting is best done just as the annual growth has reached its full length and before the buds become prominent. Annual potting is not necessary. Plants that set a heavy crop of flower buds should be disbudded, leaving but one bud or, in the case of really strong plants, two buds to a shoot, selecting the largest and the smallest to give a succession of flowers. Camellias require but little pruning and it should be remembered that cutting back a shoot deprives the plant of flowers from the resulting growths for one year. The best growth buds, and the only ones which will produce flowering shoots for the following season, are found immediately below the flowers, and by the time the latter drop the former are quite prominent. If the plants are moved out of doors during the late summer, they should be put in a shady spot at the north side of a wall, as pot plants do not like being set in full sun.

Cytisus.-C. racemosus is the "Genista" of the markets and of the general public. It is a universal favourite and a handsome plant when covered with its bright yellow flowers in spring. It is one of the easiest of greenhouse plants to grow and thrives best in a compost of about two-thirds loam and the rest either peat or 


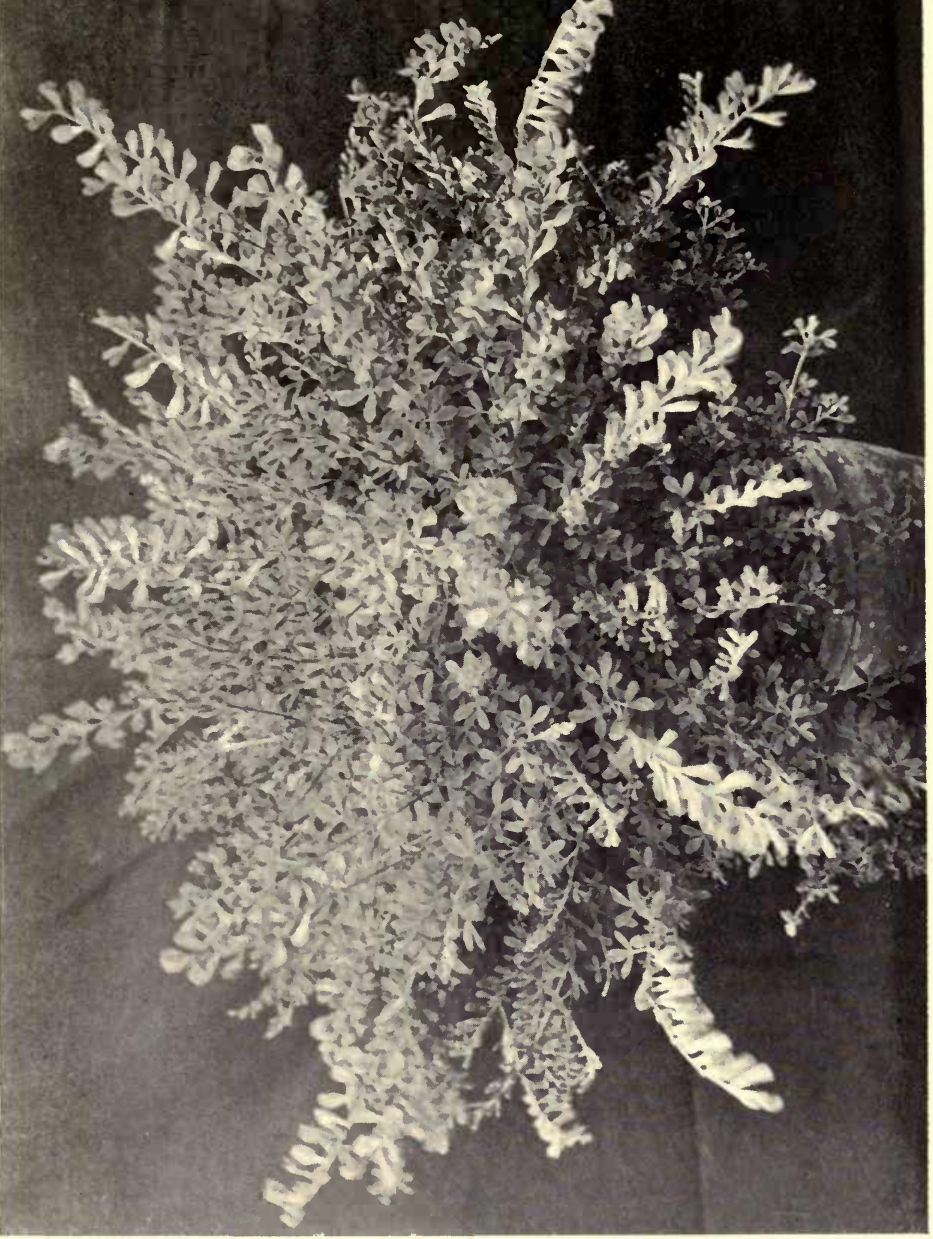


"थ

montonas 
good leaf mould, with some sand. It requires a considerable quantity of water during the spring and summer months. Its three antipathies are shade, artificial heat, and a close muggy atmosphere. A very few days in the latter will cause the plants to lose their leaves. After flowering they should be hardened for a week or two by exposure and a lessened water supply, they may then be hard pruned into shape, allowed to break into growth under glass, then turned out and repotted, reducing the balls of soil slightly, so that they will not need over large pots. From the time that the roots have resumed action until quite late in the autumn the plants should be grown entirely in the open air. The Genista does not care much for manure of any kind, but an occasional watering with clear water taken from a barrel in which a coarse bag of soot has been immersed will be very beneficial and give the plants a healthy appearance, and a dark green colour.

Daphne indica.-The exquisite perfume of this, like that of the Boronia, is perhaps its greatest charm, though a well grown plant is, when in flower, an object of great beauty. Unfortunately, well grown plants are rare and the Daphne is considered, with good reason, to be among the difficult plants to manage well. The best plants I have grown were potted in fibrous loam mixed very freely with sea-sand. A rather close corner of the greenhouse should be allotted to it, for it does not like draught neither does it do well if exposed to a great amount of sunlight, and it should never be put outside to ripen its wood. It dislikes the knife and, beyond being pinched once or twice while young to develop a bushy habit, it should never be pruned, for pruning cuts away the strongest growth buds, and those which develop from back breaks are mostly weak and remain so. Once a plant falls into bad health it seldom recovers. A healthy plant may remain in the same pot 


\section{THE BOOK OF THE GREENHOUSE}

for years. The leaves should be frequently washed either by syringing, which the plant likes during summer, or by sponging during winter.

Epacris.-These Australian Heaths make very pretty little plants; they greatly resemble the true Heaths but are stiffer in habit and bear hard pruning year after year, so that they may be kept as small bushes even when they are many years old. Their bright sprays of different coloured bells are produced in winter without forcing and, as they last well when cut, may be used for house decoration. Being rather delicate in root action great care in watering is necessary. When the plants go out of flower, cut back the shoots to about an inch above the previous year's pruning. Keep in a fairly close atmosphere for a few weeks and repot in fibrous peat and sand when the new shoots are an inch long. Do not let the roots be exposed to the air for any length of time. About the end of July, plunge in ashes in a cold frame, where the lights can be drawn off in nice weather or, if no frame be at liberty, put them outside in a position where they may have some covering in case of heavy rains. In pruning, all weak shoots should be cut out entirely. When under glass keep the plants well up to the light.

Ericas.-These, the true Heaths, are very similar to the foregoing in their requirements. A great point in their culture is to keep the plants free from mildew, which is their great natural enemy under glass. Some Ericas flower in winter, and others at various times through spring and summer, so that their general treatment must be varied accordingly. They are divided into two classes, viz., the hard-wooded and the soft-wooded. The latter may be hard pruned like the Epacris, but the hard-wooded sections will not bear this, and any pruning done to them should be but slight, some requiring none at all, being of a naturally bushy habit. 


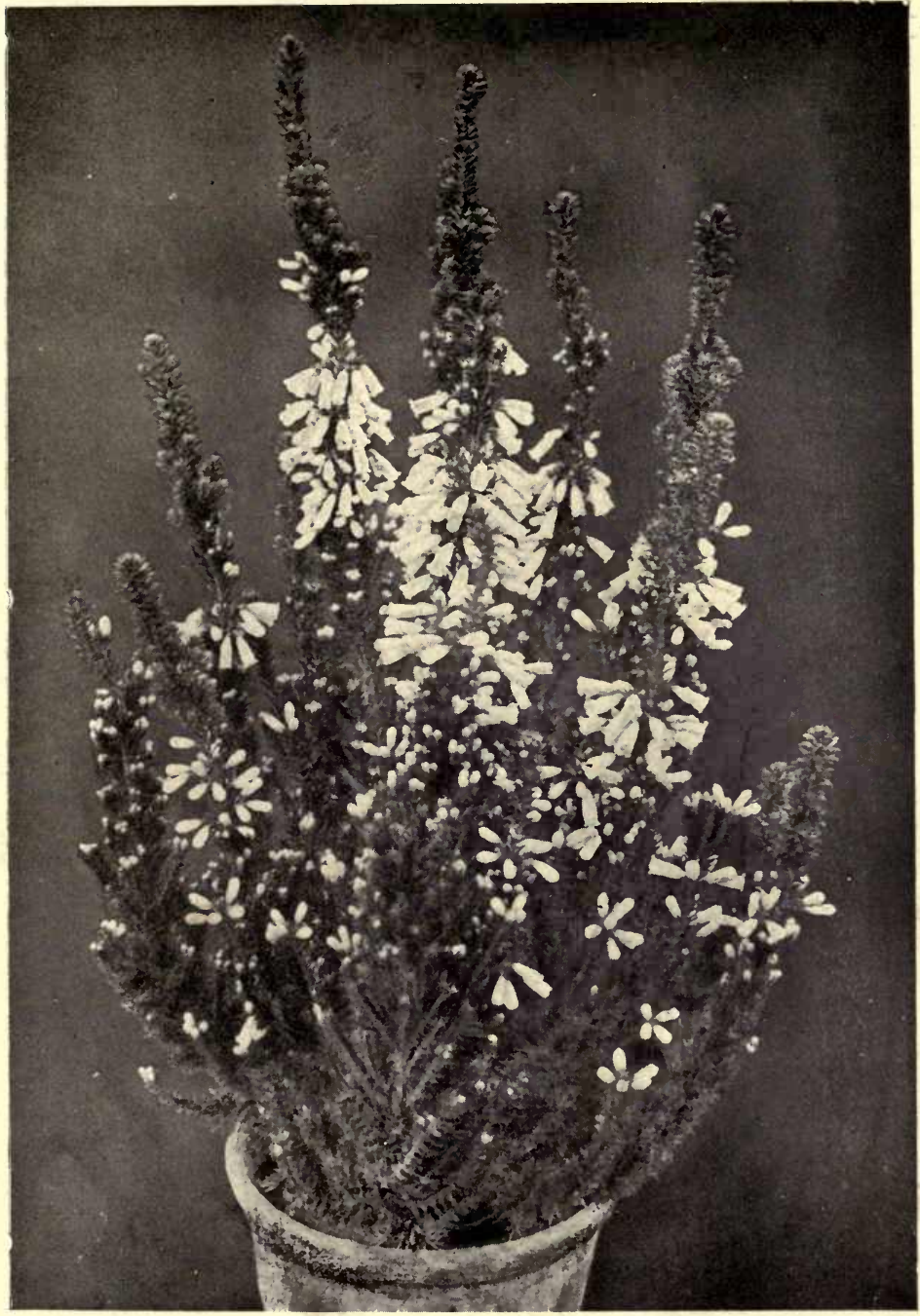




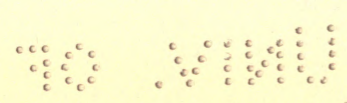
wat 
Only peat and sand should be used in the potting, and, until the plants have reached their limit in size of pot, this should be done annually, for if the roots have become much matted together from long neglect they do not take kindly to new soil.

Nerium Oleander.-This is generally known to most people by its latter name alone. It is a plant that many try to grow, but it often fails from one or other of two causes, viz., either from being allowed to become a prey to insect pests, to which it is sadly prone, or to a want of ripeness in the wood. The Nerium is essentially a lover of the open air and sunshine. The former it cannot always have, as it is not hardy, but it should spend all the warm portion of the year outside, and have a light position at all other times. It is also a plant that likes to be well fed, enjoying a good rich loam, with decayed manure and sand, and frequent waterings with manure water. It need only be pruned when it has grown out of bounds, and then it should be hard cut back in spring. This will cause the loss of a season's flowers, but will rejuvenate the plant. Water freely during summer, but give very little during the winter months.

Leschenaultia.-This genus deserves special mention as containing, in $L$. biloba major, probably the best really blue flowered greenhouse plant we have, and one of the prettiest of plants when well grown. It is a delicate rooted little plant and should not be put in the open air at any time, but exposed to sunlight in the cool greenhouse during autumn and winter. No loam should be used in the potting soil which should consist entirely of fibrous peat and sand. All the precautions mentioned in the general hints for hard-wooded plants should be observed in dealing with this, and it well deserves the trouble entailed.

Pimelia.-One of the most free flowering of green- 


\section{THE BOOK OF THE GREENHOUSE}

house plants and always a favourite. It should be grown freely and well watered during summer as it is subject to red spider if allowed to get at all dry, and to keep this insect within bounds, the plants should be well and frequently syringed. But little pruning should be done when once the plants have assumed the required shape; all that is necessary in this way being to cut off the flower heads when they pass out of bloom, as the strongest and best shoots come from the upper portion of the previous year's growth.

Rbododendrons.-Greenhouse species of Rhododendron afford very handsome plants, the treatment of which nearly resembles that of the Azalea. Many of them grow into big plants unsuited to the small house, but a section that has been much developed during the past decade or two is that of the Javanese. These are slow growing plants which may be kept in rather small pots and which flower more or less all the year round. These Javanese forms require more than the ordinary greenhouse heat and do best in the intermediate house. Scarcely any pruning is necessary further than to shorten a branch now and then for the sake of symmetry. 


\section{CHAPTER IV}

\section{Climbers and Basket Plants}

These are useful in the greenhouse in many ways. Climbers if well looked after afford an efficient shade to the plants grown beneath them, and make an attractive feature in themselves, clothing, as they do, the broad expanse of glass and woodwork with graceful growth and, in many cases, charming flowers. Many of them can only be grown well in fairly large houses, for they grow too rampantly to be confined by narrow limits. Among those named later will, however, be found some suitable for houses of any size, and they comprise the best that can be selected for the purpose. Pillars and rafters may be clothed with the more moderate growers among climbing plants, and for this purpose, too, many plants not strictly belonging to the climbers may be enlisted, as, for instance, some of the stronger growing fuchsias which are delightful and easy to grow.

Speaking generally, the methods of treating flowering climbers is to allow them a considerable amount of latitude as to growth during the summer months, and to cut them back fairly hard during winter, laying in just a thin sprinkling of the long shoots made during the previous summer, and cutting out all that can be spared of the old wood. The majority of these plants should be planted out in prepared stations in suitable positions in the borders. They mostly do well in ordinary loamy soil mixed with finely broken mortar rubbish or common sand to keep the soil open, drainage being of course pro- 


\section{THE BOOK OF THE GREENHOUSE}

vided under each station. The lovely Lapageria rosea and its varieties, however, require to be grown almost entirely in peat and sand. This is probably the handsomest greenhouse climber of moderate growth which we have, and to add to its value I may say that it is almost hardy and may be well grown in the coolest and shadiest of greenhouses with great success when once it has become established, but it should not be planted in a sunny position, and it requires a bountiful supply of water. It sometimes happens in small greenhouses that there are no conveniences for planting out climbing plants, and where this is the case I strongly recommend that basket culture of suitable plants should be substituted. Of course there are not many climbers that will adapt themselves to this treatment, but fortunately we have a few, and among these Asparagus Sprengeri is the best. Other varieties of climbing asparagus are also good for the purpose, but the one named is so easy to grow and makes such a perfect canopy when the long and light growths are trained over wires and allowed to droop at the ends that it cannot be surpassed. Planted in good rich soil in sixteen-inch baskets hung almost close up to the roof of a span-roofed house, the growths may be trained out laterally for four feet or five feet on either side, and will still be long enough to droop and complete a perfect archway of the most delicate greenery imaginable. Other useful basket plants are the Acbimenes (warm greenhouse), Fuchsia procumbens, very attractive during the winter, and ferns in variety, including many Adiantums, Nephrolepis, and Davallias.

Coming back to the climbers proper I give a selection from the best, with a few cultural details where necessary.

Clematis. - Among the clematises many, though thoroughly hardy, are grown under glass, but the most useful as a greenhouse climber is a half hardy species, 
C. indivisa, or its variety, C. indivisa lobata, the foliage of which is better in form, though the flowers are the same. The latter are pure white borne in panicles in April where cool treatment is given, but the plant is amenable to forcing, and may be had in flower at any time during the first four months of the year. The plant requires no special treatment. Only the weakest growths should be thinned out during winter, the rest being left their full length, as this Clematis flowers on the young wood of the previous year. If growing out of bounds it may be cut back reasonably hard immediately after flowering, and then allowed to grow away freely, the new growths being induced to ripen by keeping them well up to the light.

Cobaa scandens. - This remarkably free growing plant is a favourite with gardeners because of its hardiness and general thriftiness under difficulties. The typical plant has green leaves, but the most ornamental form is the variegated one in which the leaves are heavily margined with yellow. The Cobæa delights in a rich soil in which it grows almost too freely, but it may be kept within bounds by an occasional use of the knife or scissors. Once a year, either during autumn or winter, it should be pruned well back both for its own good and for the good of things growing beneath it. It has the merit of keeping fairly free from insects.

Ficus repens.-This is grown as a covering for bare walls to which it clings like ivy, and forms a complete flat mass of small deep green leaves. It grows best in good loam with which some leaf mould or fine peat may be mixed, and lime rubble or finely broken brick makes a good addition to keep it porous. Small plants are sometimes stubborn in starting away into growth, but once they begin, they grow rapidly and soon cover a large space. Once or twice a year shoots that hang loose should be cut away, leaving a flat surface. 


\section{THE BOOK OF THE GREENHOUSE}

Habrotbammus (Cestrum). - Of this there are two species well worth growing, viz. $H$. Newelli, with bright crimson flowers, and $H$. aurantiacus, in which the flowers are a rich shade of orange yellow. The latter is best known as Cestrum aurantiacum. Both are more suited for growing on a wall or pillar than as roof climbers. When once the wall space has been covered or the top of the pillar reached, the plants should every year be hard pruned (i.e. all joung growth should be cut back almost close to the old wood) when flowering is over. Any ordinary soil will grow these plants but they require abundant watering when growing.

Heliotrope.-This is not often seen growing as a climber, but I have found the old species $H$. peruvianum excellent for walls and for rafters, flowering freely almost all the summer, and certainly one of the most attractive plants to visitors. It should be planted out in not over rich soil, the leading shoots being trained up the supports till they have reached the top, which may take some years. During the winter all side shoots should be cut back close to the main stems and this will be all the pruning required during the year, as every new shoot made in spring will give one or more bunches of deliciously sweet flowers. The Heliotrope once well established is a long-lived plant and worthy of a good position in any greenhouse. During the summer it likes plenty of water, but very little during winter.

Myrsiphyllum asparagoides. - This charming climbing plant known to many as "Smilax," and sold as such on the market, is not the true Smilax nor any relative of that plant. It is one of the best of green plants, and its sprays are of great use in decorations. It likes a snug corner of the greenhouse where it may be planted out in light and well drained soil with its thick, fleshy roots or tuber scarcely buried. The growths should be trained thinly up a temporary trellis formed of pieces of fine string, 
placed vertically, and each growth kept religiously to its own string. As the annual growth is made very quickly plenty of water should be given during this period. All growth of the previous year should be cut away before the new growth comes up, otherwise the result will be a hopeless tangle.

Passifora.-The Passion-flowers in variety are quick growing and admirable plants for covering a greenhouse roof. Out of many, probably the best for our use are $P$. carulea and its variety $P$. Constance Elliot, the latter having large, white, sweet-scented flowers. All the Passion-flowers are easy to grow but many of them require more than the ordinary greenhouse temperature. As it is necessary that the wood should ripen up well, the soil should not be over rich or deep, and plenty of drainage should be given. Beyond thinning out and keeping the plants within bounds, the less pruning they get the better, as they do not like much restriction.

Plumbago capensis. - Of this there are two forms, the blue and the white, which are excellent as climbers of moderate growth. They are suited either for clothing roof, rafter, or pillar, and bear large numbers of chaste and delicate looking flowers in large bunches on the end of each new shoot. The Plumbago succeeds best when the roots are somewhat confined as to space, and should be grown in soil made very porous by the addition of broken brick and sand. It does not require a great supply of water at any time, and towards the end of autumn should be allowed to get almost dry, as this assists in ripening up the base buds of the new growth. In pruning, cut back to within an inch of the main stem or stems. Give little or no water until new shoots are breaking out, and be careful not to excite the plant into growth before winter is well over unless prepared to give it more than the usual 


\section{$3^{8}$ THE BOOK OF THE GREENHOUSE}

amount of heat for the sake of getting early flowers. Plants allowed to come on naturally are the most satisfactory.

Roses. - Many Roses make excellent greenhouse climbers, their great fault being that they are so subject to the attacks of Aphides, which are extremely persistent. Roses like a rich larder and should be grown in good loam with which some manure or crushed bones has been mixed, and manure water should be given during the growing season at frequent intervals. During the winter a much drier state of the roots must obtain so that the plants may not be too soon excited into growth. Roses vary so much in their requirements as to pruning, according to the section to which they belong, that one can here only deal with first principles. These are to cut out bodily at any time of the year all growths that are too weak or puny to flower and to lay in all the strong young wood for which room can be found without overcrowding. Some of the strong growing noisette roses, as for instance the favourite Marechal Niel, like to be grown on the "long rod" system of pruning, i.e. cutting out all flowering wood, as soon as the flowers are over, down to where it springs from the main stem and encouraging new shoots to take the place of those removed, laying them in at full length until they have flowered, when they, in their turn, are cut out to make room for their successors. Very fine flowers, and plenty of them, may be grown in this way, if vigorous root action be kept up by feeding.

Tacsonia.-Tacsonias are very rapid growing plants and only suited for large houses. The two most frequently grown are $T$. Van Volxemi and $T$. exoniensis, both bearing large, brilliant red flowers of different shades, in form much like Passion flowers, which hang face downwards from long slender stems or peduncles. The palmate, dark green leaves are very fresh and 
attractive looking. The culture is of the simplest. Plenty of water during summer, attention to training and regulating the fast growing shoots, and a rather severe winter pruning.

Tecoma.-Of the Tecomas, $T$. jasminoides is the best for a greenhouse climber and is a charming plant in every way, not too rapid in growth, and one which therefore may be easily kept within the bounds of a small greenhouse. Its beautiful, trumpet-shaped flowers are pure white, except the throat which is brilliant carmine; the flowers being individually large and borne in loose bunches. The leaflets, borne several on a stem, like those of an ash tree, are dark glossy green on the upper surface and are very attractive in themselves. This handsome plant is not much grown or known, but I strongly recommend it. Its culture is easy. It likes a soil with some peat in it, a fair amount of water in summer, plenty of light, and very little pruning beyond the necessary thinning and shortening back when growing out of bounds. 


\section{CHAPTER V}

\section{Bulbs for the Greenhouse}

To bulbous plants we are indebted for much of the brightness seen in greenhouses in winter and spring. A good many of these plants are permanent occupants of our gardens, but the vast majority are bought in annually from our Dutch neighbours with whom rests in a great measure the success or failure of their productions in our gardens, but, as we ourselves can do much to make or to mar these imported bulbs, I propose to give a few general directions which will assist towards success, these directions being more or less applicable to all deciduous bulbs whether grown at home or abroad.

We will take, as the main point which needs emphasising, the fact that, before any bulb can flower well, the flower growth must be preceded by strong and healthy root action. How natural it is for most bulbs to make the most of their time to this end may be easily proved by lifting from the garden border a bulb of a Lilium, or one of a Narcissus, directly after the annual top growth has been perfected. The chances are that such a bulb will be found to have already commenced new root action, or, if it has not, that the first rain that falls will induce it to do so. Apply the moral that this conveys to the treatment of all imported bulbs by buying at the earliest possible date, remembering that every day the bulbs are kept out of the soil, after this date, is a day wasted through one's own neglect. By an early transfer 
to their native element, the earth, good results can be assured providing the bulbs themselves be good. This brings us to another matter for consideration, viz., how to choose imported bulbs. They should be bright looking and free from blemish or mouldiness, firm under pressure and, above all, heavy in proportion to their size, for a weighty bulb may be depended on to have good flowers stored inside it.

Hyacinths, Tulips, Daffodils, Liliums, Narcissi, Crocuses, and all bulbs of like nature intended for the embellishment of the greenhouse, should therefore be potted up as soon as received and encouraged to make roots at once. Some among them have a decided season of rest after flowering, but even these will have had more than sufficient rest by the time they reach the purchaser's hands. The soil in which they are grown is in most cases quite a secondary matter, provided that it is sweet, wholesome and sandy. In dealing especially with some of the bulbous plants most suitable for greenhouse culture, I will divide them into two sections, taking first those which are usually imported annually, and going on to those which may be made permanent occupants of our houses, and which do not deteriorate under home culture, as do those of the first section.

Hyacinths. - The general treatment of the large flowered Dutch Hyacinth and the charming little white Roman Hyacinth is the same, but it must not be forgotten that, while the latter may be forced readily and had in flower at any time during the winter, the former does not take kindly to being forced, and is rarely seen good until March or April. Pot the larger kind singly into five-inch or six-inch pots, and the Romans from three to five in a five-inch pot. Good loam with a little manure and plenty of sand makes a good mixture for them, and a dash of clean sand should be placed immediately beneath each bulb which should be so set in the soil that about 


\section{THE BOOK OF THE GREENHOUSE}

one-third of it is exposed. The soil should be moist but not wet, and pressed firmly into the pot with the fingers -not rammed. Stand the pots close together on a level piece of hard and worm-proof ground, and cover them with from four inches to six inches of fine coal ashes or cocoanut fibre. Ashes are the best, but they should not be from coke or anthracite coal in any case, nor even from newly burned coal. In a few weeks the bulbs will be found to have rooted nicely and to be pushing up their crowns, and may then be taken into the greenhouse in bulk or in relays for succession. On removing from the ashes, the crowns should not be immediately exposed to light. If a garden frame is at hand, they may be stood in it for a few days and shaded until they acquire a green tint. The shading may remain on at night also as a protection from frost. Once in the greenhouse they like plenty of light. A moderate supply of water will suffice at first, but as the spikes push up, this should be increased and some manure water given occasionally.

Liliums. - There are many beautiful lilies suitable for the greenhouse, the best however being $L$. longiflorum and L. Harrissi, both pure white and grand for forcing or for cool treatment, together with the well known $L$. auratum and several varieties of the late flowering $L$. speciosum. The bulbs frequently suffer severely in transit, and those which appear to be badly blemished or to have made many new roots before they come to hand should be rejected. The bulbs should be freed from decaying scales, and the wounded portions dressed with powdered charcoal before being potted. For $L$. longiflorum and $L$. Harrissi a sandy loam is suitable, while for the others mentioned some peat should be added, the soil in each case being fibrous. Drain the pots well, pot the bulbs low down, with some sand round and under each, and do not for the present fill the pots up in the usual way, but leave room for some 

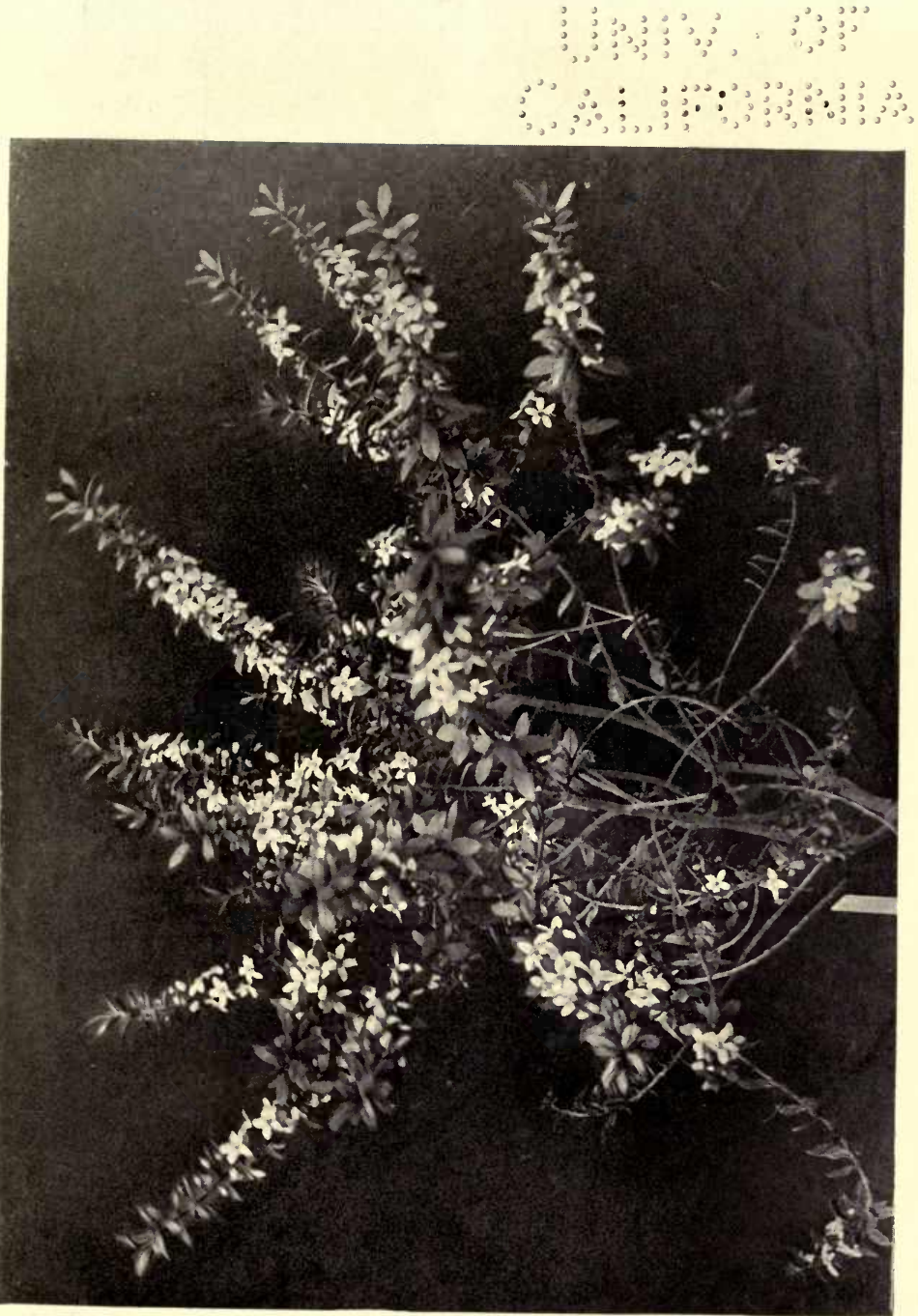

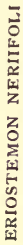


"th ynt

andrandas 
top dressing when the stem roots appear. Put the pots in a cold but rain proof frame, and give no water until the stems have grown several inches high. They may be brought into the greenhouse at any time, but only those indicated should be in any way forced. After the pots are full of roots they take a good supply of water, and manure water is a help while the flower buds are swelling. All lilies are subject to green fly when grown under glass, and are so much injured by even a slight attack that this should be strenuously avoided at all times. During the summer $L$. auratum and $L$. speciosum may be stood outside in a shady sheltered spot until the buds show, after which they are best under glass.

Narcissi.-In these notes on Narcissi it must be understood that in addition to the Polyanthus Narcissi I also include the Daffodils, many of which make excellent pot plants. These Narcissi illustrate almost more than any other bulbous plant the necessity of getting the bulbs potted early, if early flowers are desired. It suits the bulb merchants to send out all their bulbs together late in autumn, and where this practice is followed Narcissus bulbs are cheated out of two or three months of their best rooting season and suffer accordingly. From home grown bulbs lifted in July and potted at once I have had both Daffodils and Polyanthus Narcissi well in flower early in February, with nothing like the forcing that imported bulbs potted up in late autumn have taken, and the flowers, too, on the former have been much more robust. Their general treatment should follow the lines laid down for that of the Hyacinth, except that the bulbs should be potted more deeply and as many as possible put in each pot, so that a good display may be had in a small compass. After being removed from the covering of ashes, which should not be until the growths are pushing through, an ample supply of water will be necessary at all times, for drought is a thing they will not bear. 


\section{THE BOOK OF THE GREENHOUSE}

The Narcissi are essentially clean plants, being subject to no insect pests on the leaves or Hower stems, and as they require but little heat to bring the flowers on early, they will, if sufficient bulbs are grown and brought on in relays, keep the greenhouse bright and fragrant for some months. The old bulbs need not be thrown away after flowering, as they will grow well in the open garden, and after a rest of a year or two may again be lifted for pot work.

Tulips.-For pot work in winter and early spring the gorgeous tulip, from the earliest Duc van Thol to the quaintly shaped and brilliantly coloured Parrot tulip, is admirable, and, moreover, cheap and easily grown. All kinds are not alike easy to force into early bloom, but the late section brought on almost naturally will precede the outdoor flowers; and as these late varieties are the most robust, and have flowers of high quality, a portion at least of the pot plants should consist of them. The bulbs selected should be bright nut brown in colour, glossy looking, and heavy. They may be potted pretty closely together, as they do not require much room, and the bulbs should be well buried in the soil not less than an inch of which should cover them. Place them under a covering of ashes as recommended for hyacinths, and do not put them into the greenhouse until growth has begun. Tulip bulbs like those of the Narcissi may be ripened off in the pots they have occupied, and used for planting out in the open garden. Home grown bulbs serve very well for late pot work, but for early work the Dutch grown bulbs are best.

Gladioli.-Among the Gladioli there is a charming little section of which $G$. Colvillii is the species, and from this we get two or three varieties-a white one known as The Bride, a rose-coloured form, and another with a white ground and clear rose stripes down the petals. All are useful for the greenhouse, and flower early 
before outdoor flowers are plentiful, though they will not bear forcing in the ordinary sense of the word. As the bulbs are small they may be put several in a pot, and being rather tall growers the pots that suit them best are those seven inches or eight inches in diameter. Fill the pots to within three inches of the top with sandy soil, on this place the bulbs and cover with two inches of soil. Do not plunge under ashes, but place them direct into a cool frame or on the shelf of a cool greenhouse, and allow them to come on gradually. Smaller pots than those advised above may be used, but the bulbs rarely succeed well in less than six-inch pots. When roots have been formed, and the plants are growing freely, they will take a rather bountiful supply of water, if the pots are well drained as they should be.

Ixias.-With these, though they are distinct, may be included the Babianas and Sparaxis, as the same treatment is required by all, and all are charming though much neglected plants. The flowers have a wonderful range of colour, and one at least, Ixia viridifora, stands unique among flowering plants, for its petals are of a beautiful and brilliant green hue. The probable cause of present-day neglect is that these plants do not bear the influence of artificial heat at any time, and in these days when the culture of things which require or like heat is attempted in almost all greenhouses, such plants are bound to fail. The small bulbs should be potted up from five to eight in a five-inch pot. Half sandy loam and half leaf mould suits them, and if the drainage is covered with a little of the fibrous loam and immediately on that is put some well-decayed cow-manure, the roots will revel in the latter just at the time when the flower spikes are being thrown up. The bulbs should be covered with about an inch of soil, and the pots then stood in a cold frame. No water must be given until growth commences, and an overdose is to be avoided at all times. 


\section{THE BOOK OF THE GREENHOUSE}

The plants should be shielded from draught, and should have a cosy corner near the glass after being brought into the greenhouse. Though I have here included them in the section devoted to imported bulbs, they may be well grown at home, if, after flowering, the growth is allowed to ripen off gradually under glass, and when ripeness is complete the bulbs are shaken out and put into paper bags, which may be kept in a dry cool place till potting time (October) comes round again.

Tuberose.-Though the tuberose (Polianthes tuberosa) is mostly used as a forcing plant, it may be grown cool throughout, and will then flower in the greenhouse late in summer. The bulbs should be potted in February or early in March in equal parts of loam, leaf mould, and decayed manure, with plenty of sand; two-thirds of each bulb should be covered, and the soil pressed quite firmly around it. A single bulb in a five-inch pot will be sufficient, and this is better than putting more bulbs in a larger pot. Water well after potting, and stand in a cold frame until the pots are filled with roots and growth is commencing. Very little water will be required for several weeks, but when really growing they take a good supply, and are helped with manure water. Tuberoses delight in being well syringed daily when in growth, and syringing also helps to keep down red spider, to which they are subject in a dry atmosphere. They are all the better for being kept in the frame till they have made a foot or more of growth, provided they are well looked after as to ventilation, which should be abundant in nice weather.

\section{II}

We come now to the second section of bulbous plants, according to my classification, viz. those which may be made permanent occupants of our greenhouses and 
gardens, and though, among these, we may miss some of the brilliancy of colouring and wealth of blossom that is to be had among the most popular of the previous section, we gain in the knowledge that all the success met with in growing them is the result of our own efforts and care, and year after year we watch their progress with enhanced interest.

Crinums.-Though most of the Crinums are stove plants or enjoy a great amount of heat in the growing season, a few such as C. mooreii, C. macowanii, C. capense and its hybrids are very handsome greenhouse plants bearing large umbels of white or delicately tinted flowers. The plants are mostly evergreen, like a plentiful supply of water in the summer, and should not be dried off in winter. The root action is strong and large pots are necessary. Fibrous loam, together with a little peat, plenty of sand and, if at hand, a dash of crushed bones will be found a suitable mixture in which to grow them. The bones are of service as they supply food for some years and, therefore, when the biggest size of pot is used, it will not be necessary to repot every year, though a good top-dressing of rich soil may be applied in spring, which is also the time to repot those that need it. Shade should be given while the leaves are young and during the time of flowering, but after this they should have full light and a reduced supply of water, though they must not be dried off like many other bulbs. If increase of stock is desired, offsets may be pulled away from the parent bulbs when potting.

Freesias.-The Freesia is an ever welcome flower, its sweet scent and delicate flowers being always acceptable, and as it may be well grown in small pots it is suitable for greenhouses of any size. Many people buy in a fresh stock of bulbs every year as they fail to flower the home grown stock well, but it is not necessary to do so when it is thoroughly understood that the failure is due 


\section{THE BOOK OF THE GREENHOUSE}

to the want of ripeness. By proceeding on the following lines success is practically certain. The bulbs should be potted up in July or early in August, putting a dozen in a five-inch pot or a proportionate number in a six-inch pot. Drain the pots well, fill them to within two inches of the top with soil composed of two-thirds loam and one-sixth each of sand and decayed cow manure. On this put the bulbs and cover with an inch of the same mixture. Stand on ashes in a cold frame and in a few weeks the growth will appear. Keep close up to the light and water lightly at first, but in increasing quantity as growth increases. Move to the greenhouse shelf near the glass before frosty nights come on, and do not permit the plants to be in a draught. Use no forcing tactics to bring the flowers on, as the flowers so produced will be flimsy. If a succession is wanted, this may be gained by potting the bulbs in successional batches beginning early in July and finishing in September. After flowering do not fail to water freely until all the leaves have turned yellow, and then cease. By this time the bulbs will have finished their growth, and the next thing is to ripen them by standing them on the hottest and sunniest part of the shelf until potting time again comes round, giving not a drop of water during this period. Bulbs so treated start freely into growth directly they are potted, while half ripened ones, such as are often found among home-grown bulbs, often refuse to start at all. Freesias being frail in growth require some support and this should be given early and added to as they grow taller. Stock may be fast increased by taking care of the small bulbils found in the soil at potting time, and these come to flowering size in a year.

Hamantbus.-This very attractive and easily grown genus of bulbous plants, known also as the Blood Flower, deserves to be more grown than it is, and 
especially so by amateurs, for it gives but little trouble and is quaint as well as pretty. A few of the best would be $H$. sanguineus, $H$. natalensis, $H$. Katherinoe, and $H$. insignis. These are plants that do not often require repotting, as they like to be cramped for root room, or at least they flower best under such conditions. Need of potting will be indicated by a falling off in size of leaf. Pot, when growth is beginning, in a mixture of loam, peat, and sand. For the latter, pounded mortar rubbish may be substituted. After the leaves of a season's growth have been perfected, rest should be induced by withholding water, and the plants may then be stored away in the background or under the stage, where they can be kept dry till the flowers show. Increase with these plants is not rapid, but off-sets may be taken when potting and grown on in small pots for the first year, taking care not to over-water them.

Hippeastrums. - Most of the Hippeastrums, or Amaryllis as they are more often but erroneously called, are stove or hothouse plants, but among them are a few very beautiful greenhouse species and varieties, for which room should be found in all collections. Perhaps the best are $H$. aulicum with immense lily-like flowers, $H$. Johnsonii, $H$. vittata, $H$. pardinum, and $H$. pratense. All are sub-evergreen and should not be entirely dried off, but, as with most other bulbs, there should be a distinct falling off in the amount of water given after the leaves begin to ripen. Pot when necessary, which will be only every third or fourth year, when new growth begins, in a mixture of very sandy loam, a little leaf mould, and a small handful of crushed bones to each pot. For a single flowering bulb a six-inch pot will be a good size, but I like to have these greenhouse forms potted on with their offsets left intact, so that one may eventually have a good display of flowers instead of a single spike. When the offsets become plentiful, bigger pots will of course 


\section{THE BOOK OF THE GREENHOUSE}

be wanted. In potting, half bury the bulb and pot firmly. Water carefully to begin with, but plentifully as the leaves expand, and those plants which have not been repotted should be given manure water at least once a week in the growing season. Strive to keep the leaves green and perfect as long as possible, as they are necessary to assist the bulbs to finish up properly. A light position should be given during the whole period of activity. Increase by offsets, which should not be removed until half grown towards flowering size, or by seeds which germinate freely enough in a fair amount of heat, but take some years to reach the flowering stage or size.

Imantophyllums. - Imantophyllums, or Clivias as they are known to some, are very handsome plants even when not in flower, being evergreen with dark green, long, arching leaves. They are among the most easily managed of greenhouse bulbs, as they require potting but seldom, and are subject to no insect pests. During the summer and until they have flowered, which bulbs of flowering size are practically certain to do every year, they like more than the normal amount of water, and enjoy being syringed frequently. Later on, one should reduce the supply and leave off syringing, as too much water after growth is finished causes the leaves to decay at the tips. These plants bear a considerable amount of shade with impunity, and it does not appear to interfere with their flowering, provided their general treatment is right. When potting, use a mixture similar to that recommended for Hippeastrums, and pot firmly. Increase by off-sets or divisions, and keep these almost dry at the root till new roots form. Long-established plants may be kept in health and vigour by removing some of the surface soil in spring and replacing it with some new and rich material.

Lachenalias.-One of the hardiest of our indoor bulbous 
plants, neat and rather small in growth, quaint in flower colouring, and attractive in leafage, the Lachenalia is a great favourite as an early flowering plant that requires little or no artificial heat, and is excellent either for growing in hanging baskets, or in small pots that may be used for fringing our greenhouse benches. Out of the many species and varieties, perhaps the three best are $L$. tricolor, with green, red, and yellow flowers and dull purple spotted leaves; L. pendula, a strong grower; and L. Nelsoni, with its golden flowers borne from fifteen to twenty on a scape, perhaps the best of them all. Lachenalias should be potted every year in August, putting about six bulbs in each five-inch pot. The soil should be rich and very sandy or gritty, road grit suiting well as a medium for keeping the soil open. One half loam, the other half equal quantities of leaf mould, dried and finely sifted cow-manure, and sand will suit well. Plant the bulbs in this mixture half an inch deep, and put the pots in a cold frame; give one watering, and let this suffice till growth gets well advanced. Leave in the frame until sharp frosts are imminent, then remove to a cool greenhouse shelf where plenty of light may be had. Water freely when the spikes begin to show and until growth ceases, then dry off in the sun and keep dry until potting time comes round again.

Basket culture has been alluded to, and the way to set about it is to line the baskets with some fibrous soil to prevent the finer particles from falling through them, put on this a thin layer of finer soil, and in this place the bulbs with their crowns looking outwards towards the sides and bottom of the basket, but so placed that the growth will come through between the wires. Fill up with soil, then place a slate or board across the top to prevent the soil from falling out when the basket is inverted, as it should be on to a pot in the cold frame. On removal to the greenhouse later on, when the growth 
has come through, it may of course be hung up in normal position, and the plants will then be clothing the bottom and sides of the basket. Lachenalias are readily increased by saving the small bulbs found when potting.

Nerine.-The best known of the Nerines is the Guernsey Lily ( $N$. sarniensis), of which $N$. s. venusta is the brightest form, bearing umbels of the most brilliant scarlet flowers. Another good and brilliant form is $N$. curvifolium or Fotbergilli. As Nerines flower mostly in the autumn and the leaves are made after the flower spikes are well advanced, these plants require an abundant supply of water at a season when other bulbs are getting a reduced supply. This should not be overlooked, a good rule being to give plenty of water from the time the leaves appear until May, and none afterwards. Full light must be given when growing, but at other times they may be stored in any dry and frostproof place. Established plants are best without repotting or division until this is forced on the grower, as it generally means loss of vigour for at least a year. The soil best suited to growth is loam, leaf mould, and sand in about equal quantities. In this compost, imported or recently divided bulbs should be firmly potted, using rather small pots and giving only sufficient water to prevent shrivelling until roots are forming freely.

Sprekelia formosissima.-This very handsome plant is known also under the names of Amaryllis formosissima and the Jacobæan Lily. The velvety, deep scarlet flowers are not always freely produced, owing to insufficient ripening of the bulbs. When the leaves have faded, a thorough exposure to the sun on a shelf under glass is essential to success. During the rather short season of growth give plenty of water and occasional doses of liquid manure to feed the bulbs, then, when the leaves have ceased growing and are turning yellow, withhold water entirely, and seek to make the most of sunlight 


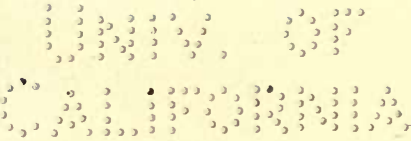

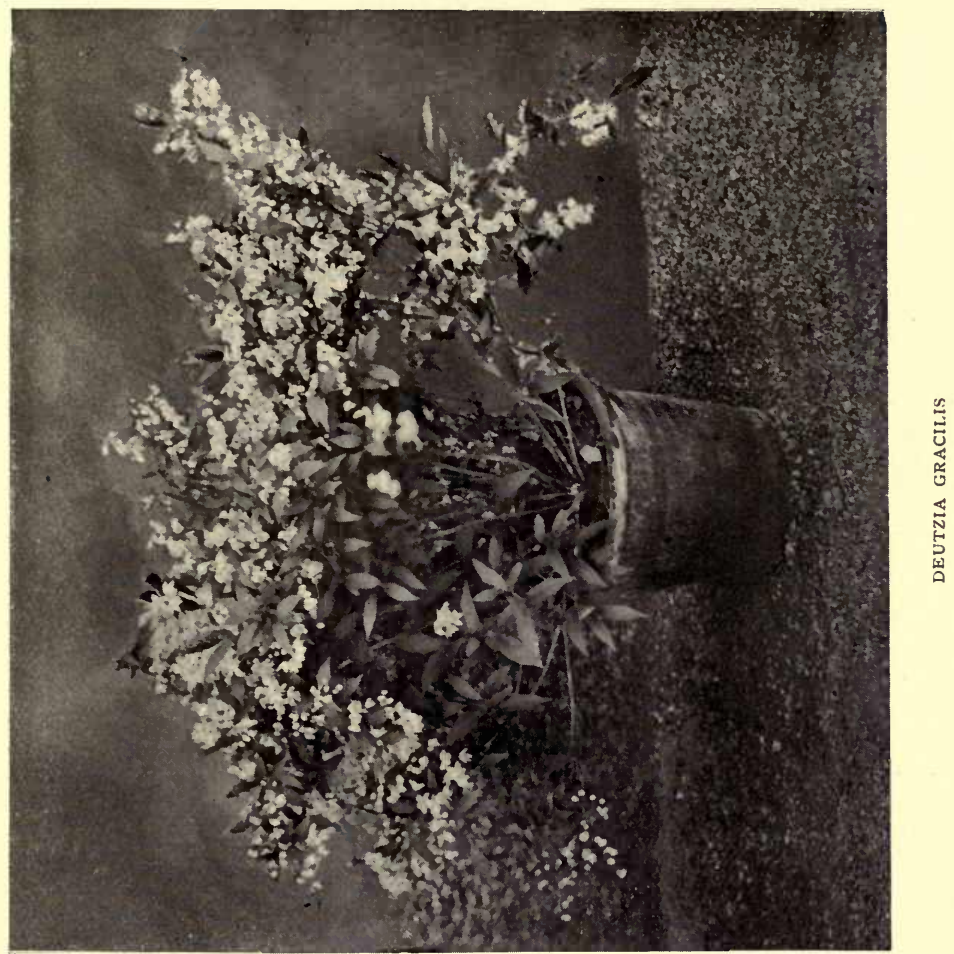




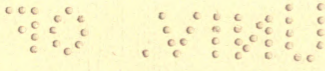

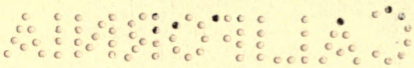


for ripening purposes. A big, soft bulb will never flower, no matter how well fed it may be, and keeping the plants dry without exposing to the sun is insufficient. Sprekelia bulbs need not be potted often, and are best grown four or five together in a six-inch pot, using for them fairly rich soil to begin with.

Vallota.-The "Scarborough Lily" is a puzzle to growers, for it is often found doing best where it gets least attention. The primary cause of this is that it does not like root disturbance after once being established. Equal parts of loam, leaf-mould, and road grit or sand will suit the plants; half the sand should be mixed with the soil and the other half distributed immediately round the bulbs. Vallotas being evergreen must not be dried off nor kept without water at any time, but care is necessary not to overwet the new soil and so turn it sour before being occupied with roots. Pot very deeply, entirely covering the bulb. Established plants must be watered freely during the growing season, which is during autumn and winter, and they like occasional doses of liquid manure. Vallotas are mostly increased by off-sets, but seeds germinate freely in a greenhouse temperature. Seedlings take some years to reach flowering size, but they then make excellent and generally very healthy plants. They should be potted four or five together in a small pot while young, and, afterwards, the clump so formed should be potted on intact. 


\section{CHAPTER VI}

\section{Greenhouse Plants from Seeds}

IN this chapter I propose dealing with the most popular of those greenhouse plants, the principal, and in most cases the only, method of raising which is by sowing seeds. They include annual, biennial and perennial plants, but may all be classed together, as their common end, when once they have flowered, is to be thrown away to make room for other seedlings in their turn. As each differs from the other in essential details, the general remarks on them will be few, but most of them agree in liking a tolerably rich, loamy soil, with plenty of grit in it to keep it open and free working for the roots, and do not like it made firmer, when potting, than can be done under pressure of the fingers. The root action in most cases is vigorous and free, and until they reach their flowering pots they should never be allowed to become pot-bound, i.e. their roots should not mat together round the sides of the pots, as this gives the plants a check from which they rarely recover. By judicious selection and treatment and by the enlistment of the services of the garden frame during the summer, an all-the-year-round display of flowers may be had from this section of plants alone. A word of advice may be given which is applicable to all these plants, and that is to be sure in all cases that a good "strain" of seeds is selected for sowing. It takes no more skill or attention to grow a good plant than to grow a bad one, and there are both good and bad seeds on the market. All the 
skill one may use in growing the latter will never result in good plants. Go always to a reliable seedsman, whether he be in a large or a small way of business.

Balsams. - Sow seeds thinly about the end of March in pans of rich loamy soil mixed with decayed manure and sand. Water in, cover with a sheet of glass and put in a temperature of $60^{\circ}$. As soon as the seedlings germinate, raise the seed pan close to the roof glass in a position where they will get plenty of fresh air. If left in a close atmosphere and at a distance from the light the seedlings become "drawn" and useless. Pot off singly, always in rich soil, when they are about two inches high, using small pots and sinking the plants low, so that the cotyledons or seed leaves touch the soil ; and continue repotting, each time before the roots get matted, until reaching the flowering pots, which should not be less than eight inches in diameter and, for really fine plants, should be bigger. Always keep well up to the light and every few days turn the pots round, so that each side of the plant shall be well balanced. The plants will eventually branch out all round, and when these branches are long enough they should be gently drawn down and tied in position to form a bushy bottom. No crowding must be allowed. When the first flower buds show, they should be picked off from the lower parts of the plant, allowing none to develop until the plant is well formed; then discontinue this disbudding and commence to feed with weak manure water, which should always be used in a clear state, never thick, for all plants; continuing this feeding as long as the plants are worth keeping. The rather high temperature recommended for seedlings should be gradually reduced as the outside temperature gets warmer, until the ordinary greenhouse conditions are reached. Well grown Balsams are very handsome plants and last long in flower.

Calceolarias. - The seeds of the herbaceous Calceolaria 


\section{THE BOOK OF THE GREENHOUSE}

are particularly small and need care. In July a seed pan should be drained and filled with a mixture of loam and leaf mould in equal proportions, together with a liberal sprinkling of sand. This should be pressed into the pan perfectly level and with some very fine soil on top. Water the soil through a very fine rosed water pot until it is well moistened throughout; on it then distribute the seed as equally as possible and cover with the merest sprinkling of very finely sifted soil and sand. So slight must be this covering that many growers do without it altogether and trust to the seeds finding their way into the soil sufficiently to germinate. Put the pan under a hand light or large bell glass in a damp, shady corner out doors. It is advisable to raise the pan on an inverted pot with its rim standing in a saucer of water; this will prevent slugs from getting at it and is a wise precaution. Keep without air till the seeds germinate, as by keeping close we prevent evaporation and the necessity for watering, which is a dangerous operation with such tiny seeds. If the surface does, however, get dry, dip the pan into a tub of water, holding it level and high enough to prevent the water from breaking through the surface, for a few minutes, when it will have absorbed sufficient for its needs. When the seedlings show, give air daily. When large enough, prick off in soil containing, in addition to that advised for seeds, some decayed cow manure. Pot off into three-inch pots when big enough, and the larger plants will need one more potting before winter, going then into five-inch pots. In February, pot in the flowering pots, which may vary in size with the strength of the plants, but should not be less than seveninch. Careful watering, never letting the soil become dry, is necessary, and so too is shade at all times. Fire heat these plants abhor, and they are often grown in cold frames throughout, but must be protected in some way 


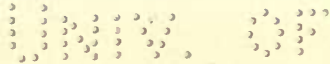

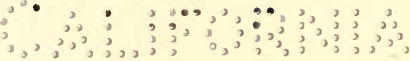

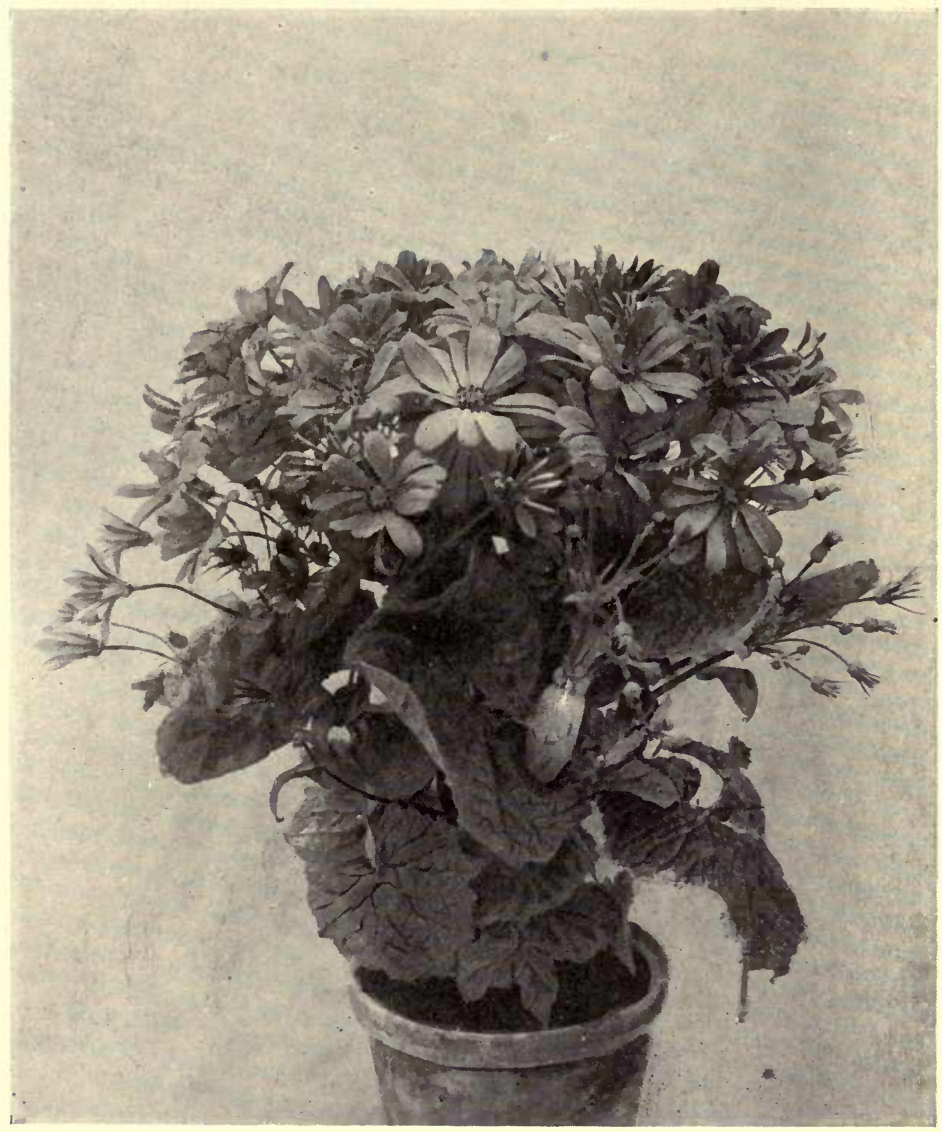




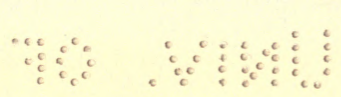

and 


\section{GREENHOUSE PLANTS FROM SEEDS 57}

from actual frost. If they have to go into an ordinary greenhouse, keep them as far removed from the hot water pipes as possible. Green fly is very troublesome and must be kept off them at all costs. The leaves are soft and readily injured by insecticides, so that it is important to vaporise lightly and often with one of the Nicotine preparations.

Cineraria.-Sow seeds any time during May in pans of light soil placed in a cool, shady corner of a garden frame. Shade must be given at all times through the summer, and the garden frame placed at the back of a wall with a northern aspect is best for them until winter frosts will allow of it no longer. Two things on which one may be quite emphatic, are that the plants are tender and easily injured by frost, and on the other hand that they do not like artificial heat, though they must have it at times to keep them safe. When the seedlings are large enough to handle, prick them off a couple of inches apart into other pans, the soil for which may be half loam and one-sixth each of decayed manure, leaf mould and sand. Before they become crowded, pot off singly, using good drainage, as they like plenty of water; never letting them become pot-bound until the final size of pot is reached. Plants in six-inch to eight-inch pots are the handiest, and they should be well established in these by the end of September. They will be much benefited by night dews during summer, and the frame lights should be drawn off every evening when the weather is fine and calm. A cool ashes bottom is good for them in the frames, and when moved to the greenhouse they should be kept well away from the pipes. Cinerarias are very subject to green fly and should be frequently treated as advised for Calceolarias.

Campanula pyramidalis.-This, the tall growing Chimney Campanula, is really perennial, but for ordinary purposes is best sown yearly. Seeds sown in April or May do 
not make flowering plants until the autumn of the next year, but are worth the waiting for. They may be raised in a cold frame, the young plants being grown on so that they occupy fuur-inch pots for the winter, which they should spend in a cool house where they may be kept rather dry at the root. In early spring, pot on into sixinch pots, potting very firmly, and from these again when full of roots into eight-inch or nine-inch pots. This last potting should take place just as the stems appear to be lengthening, which will be an indication of running to flower; they will then give a fine display of flowers, and if the earlier ones are picked off as they fade, others will come on in succession. There are both blue and white flowered forms of this fine Campanula, and seedsmen also sell now a dwarfer form which has been selected and which is useful for small houses. This Campanula is hardy if it can be kept dry through the winter. It may be wintered outside in the garden frame, if the lights are water-tight, provided the pots are plunged to their rims in ashes.

Celosias.-The very elegantly plumed Celosia pyramidalis is here intended, but with it may be classed the ever gorgeous and quaint Cockscombs which many people delight in growing. Except in the early stages, they may be grown in the greenhouse, where they are very attractive and bright through the autumn. To raise them, one must command a night temperature of about 60 deg., more rather than less, and this may be produced by making up a hot-bed of stable manure and leaves on which to place a garden frame. Such a hot-bed is one of the greatest boons to the owner of a garden which does not contain a hot-house, for in it may be raised and propagated very many things impossible without some such aid.

Sow the seeds in March or early in April in well drained pots of light soil containing a considerable 


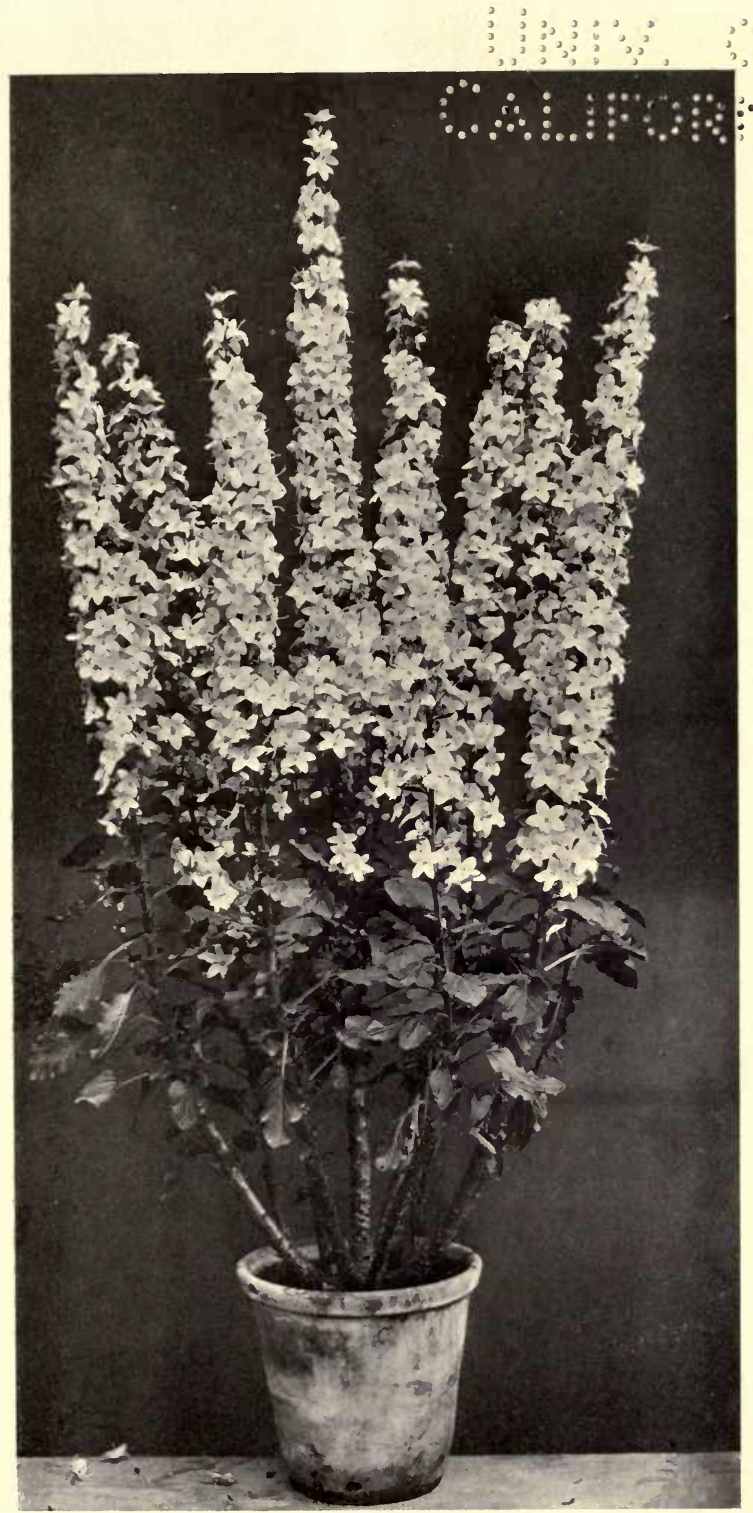

CAMPANULA PYRAMIDALIS AI.BA

Reproduced by permission of Messrs. Sutton $\mathcal{E}$ Son 


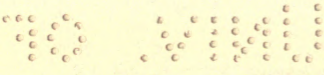

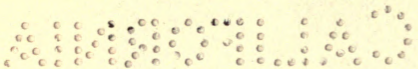


amount of leaf mould and sand, and plunge in the hotbed. The seeds germinate quickly and should always be kept well up to the light, this being especially necessary with the Cockscombs, which are never considered to be well grown unless they are dwarf. Pot the seedlings off as soon as ready into three-inch pots. If large plants are desired they must be frequently repotted, and this is very essential with the Cockscombs; but plants of the pyramidalis section may be kept in small pots until they show their colour, when the rubbishy forms, of which there are sure to be some, may be thrown away and the rest potted on in time to make useful plants in six-inch pots. At the final potting, the soil should be somewhat coarse and must contain a considerable amount of decayed animal manure. Celosias do not care for a lot of water at the root but like considerable humidity in the atmosphere, and should be freely syringed in fine weather as they are rather subject to red spider. I prefer to keep them in frames and on a moist bottom during summer. If they can remain on the hot-bed so much the better. Ventilate freely during the day, but shut up early after syringing well.

Cyclamen.-The Persian Cyclamen is better grown now than ever it was, and especially so by growers for market, who get wonderful results under an express system of culture which is not possible to those who cannot devote whole houses to them. One thing, however, we have learned of late years from these examples, is that young plants well grown are better than the old ones which used to be kept year after year at the cost of much trouble and many failures. The Cyclamen cannot be called a cool greenhouse plant, for it likes a fair amount of heat when actively growing. Seeds should be sown in August, using new seeds always, in pans of loam, 


\section{THE BOOK OF THE GREENHOUSE}

leaf mould and sand, putting them in a temperature of about 55 deg. Keep moist but not wet. When each plant has made two or three small leaves, pot off singly in similar soil, taking care not to bury the corm entirely. Continue to keep up a growing temperature and have the plants nearly close to the glass, but in a position where they may be shaded during the hottest part of the day. Syringe freely two or three times a day and see that they never get dry at the root. In June pot into the flowering pots, using two-thirds loam, one-third leaf mould, with plenty of sand added. Pot in five-inch or six-inch pots according to the strength of the plants. When nicely rooted, move to a frame and keep them fairly close for a few days. Avoid over-watering at this period, but syringe twice a day with soft water. After a while, ventilate with more freedom and be sure to give the plants ample room. When the nights grow cool, remove to a warm part of the greenhouse. Feed with manure water when the flower buds show. Cyclamen is subject to green Ay, and sometimes is pestered also with thrips. Neither must be tolerated or the plants will suffer.

Humea elegans. - Seeds of this attractive biennial should be sown in May in pots of loam and peat equally proportioned and mixed with silver sand. The seeds are light and easily washed away, so it is best to water the seed pot before sowing them. After scattering the seeds cover them with the merest sprinkling of fine soil. The seeds germinate slowly but should not be raised in heat, a shady corner in a cold frame with a sheet of glass on the seed pot to conserve moisture being what they need. Pot off the seedlings into three-inch pots, and when the roots come to the sides pot again into five-inch pots. This last potting should be in September or early in October. Careful watering is a salient matter in dealing with this plant, never giving an overdose, and never allowing dry- 


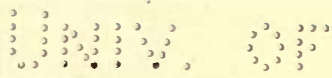

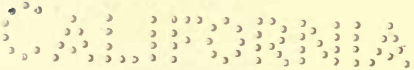

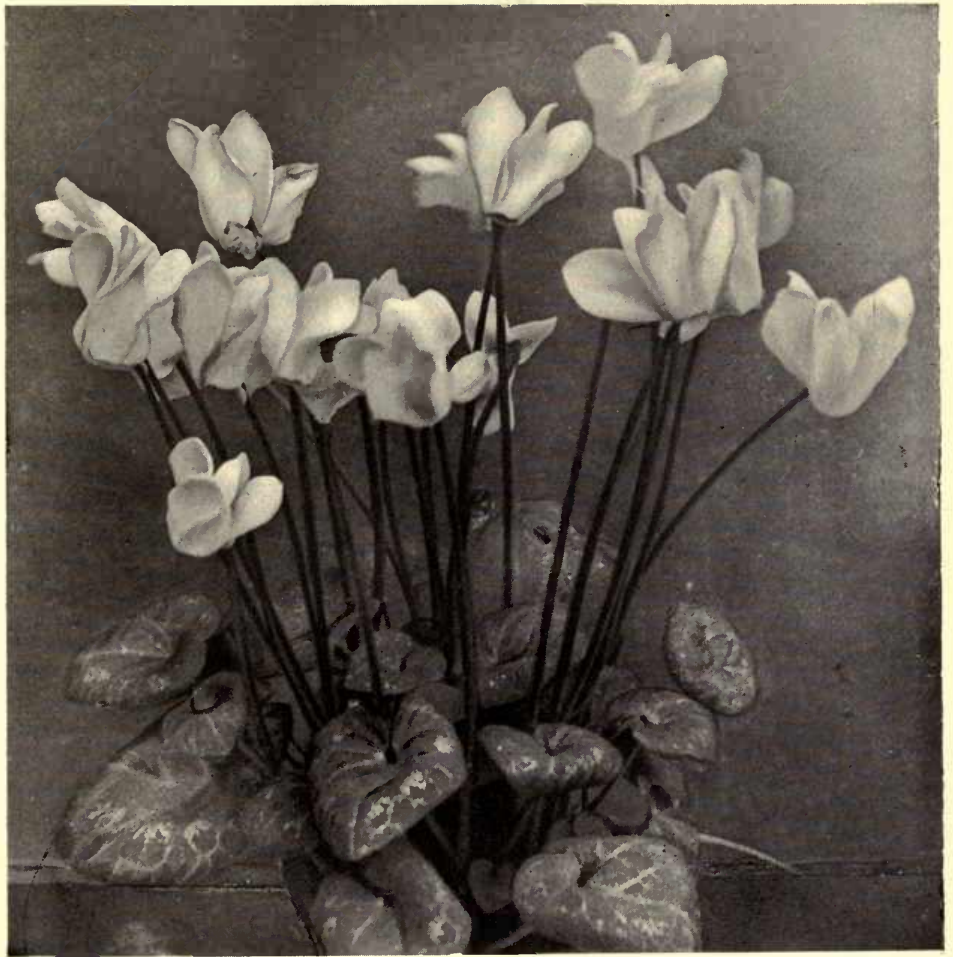

CYCLAMEN PERSICUM 
ie

and 
ness. Keep in a cool house all winter, just safe from frost. In spring re-pot into seven-inch pots and later on into larger ones, using at each potting similar but more lumpy soil. Give manure water when the roots have filled the pots given at the last potting. Humeas like some shade from bright sun and to be always amid cool surroundings, but should never be syringed overhead for this they do not like. Like many other greenhouse plants, the Humea enjoys frame culture during its first summer and up to the time when frost is to be feared.

Primula sinensis. - Chinese Primulas are probably the most popular of the Primrose family, no greenhouse display in spring being considered complete without them. They are comparatively easy plants to grow and not much troubled with insect pests, though the ubiquitous green fly has a penchant for them when young. Seeds may be sown from March to June according to the time flowers are wanted most. The earliest will flower in autumn and winter but suffer by comparison with those that flower in spring. The seeds, which are fairly large, should be sown in pans containing a mixture of leaf mould, loam and sand. Early sowings will need a little heat, but later ones are best raised in a cool frame. Cover the pan with glass till the seeds are up, pot off when ready into small pots and continue repotting as they need it. A useful size of pot to flower in is six-inch, but they may be grown in various sizes according to taste. At the later pottings, manure may be added to the soil, which should always be kept on the light side by using plenty of leaf mould. Frame culture is best through the summer, and on fine nights the lights may be drawn off, the plants being grateful for summer dews. They must have ample room when growing and a fair amount of ventilation to keep them sturdy. Shade, too, will be needed in hot weather. Plenty of water must be given in the summer and a 


\section{THE BOOK OF THE GREENHOUSE}

lessened supply towards winter, but never let them be quite dry. In potting keep the plants low down in the pots. It was customary years ago to keep the short stem under the leaves above the soil, but this was a mistake and a cause of trouble. Move to the greenhouse before the dull and humid weather of late autumn comes on, and give a temperature of about $50 \mathrm{deg}$. There are many other valuable Primulas to be raised from seeds which can only have mention here. Their treatment is to some extent similar, except that they will do with a lower temperature in winter. Among the best are $P$. verticillata (the Abyssinian primrose), $P$. obconica, $P$. floribunda, and the new hybrid between the first and last of these, named $P$. Kervensis.

Schizantbus.-For flowering in pots early in summer the schizanthuses are very bright and light-looking. They give but little trouble to grow, and the butterflylike flowers of $S$. retusas are very interesting in form. Seeds should be sown in August, either in the six-inch pots in which they are to flower or in an ordinary seed pan which should be put in a cold frame. If the former method is practised, soil composed of loam, leaf mould and decayed manure should be used, and the seedlings simply thinned out eventually to about three in a pot. Soil without the manure will do for seedlings to be re-potted into, and this is perhaps the better way, providing they are not allowed to get big before removing them from the seed pot. In any case the soil for the flowering pots should be fairly rich. Grow on in the cool frame till the nights get cold, then move to a light shelf in the coldest part of the greenhouse, as it will not do to tempt the flower spikes to run up too soon. Grow on as slowly as possible and water carefully until the pots are filled with roots, after which a little manure water will be helpful. 


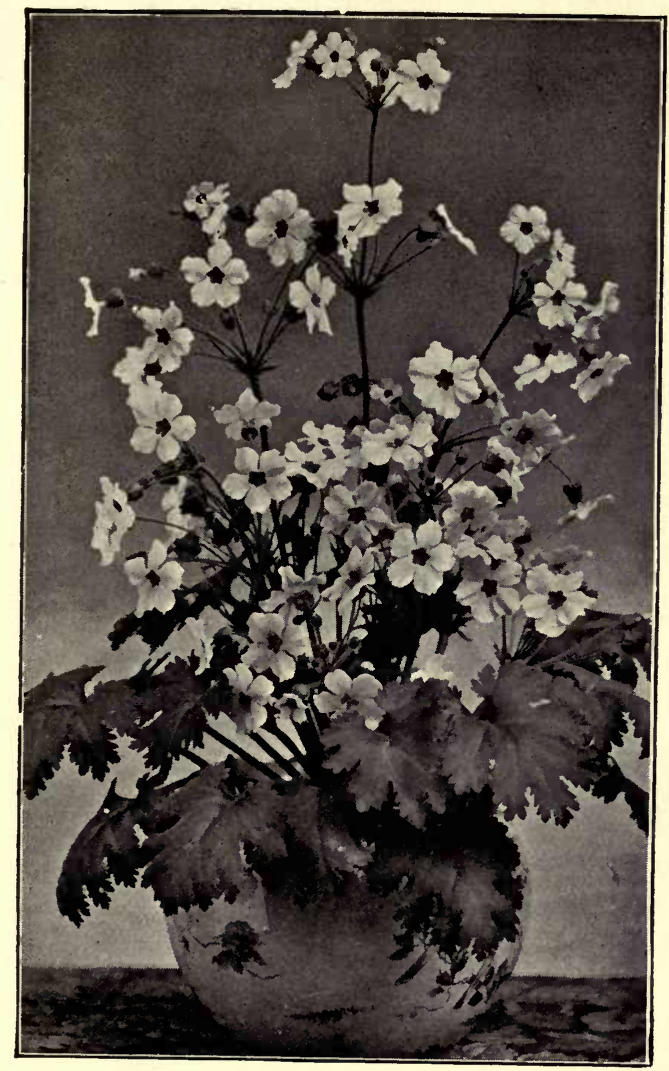

SUTTON'S WHITE STAR PRIMULA

Copyright by Messrs. Sutton EN Sons 


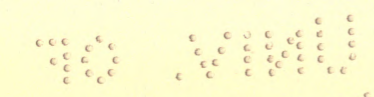

a dist 


\section{CHAPTER VII}

\section{Miscellaneous Greenhouse Plants}

As may be readily understood by the heading under which these come, there can be no general rules laid down for their culture beyond those first principles of plant culture which will be found elsewhere in this little work. Some, such as the Chrysanthemums, Cannas, Fuchsias, Salvias and Begonias are fairly gross feeders, whilst others such as the Francoas, Kalosanthes, Streptosolens, and one section, at least, of the Pelargoniums would be spoiled by high feeding. The Chrysanthemum can here only be treated of in its general aspect as a decorative plant for the green-house and not on the fuller lines of growing for show or large blooms. The group of miscellaneous plants that may be used for greenhouse embellishment is a large one, of which many members cannot be included here, but my selection will be found to include the most worthy of them.

Abutilons.-Abutilons are mostly vigorous growing plants that do not much care for the confinement of a pot, and many of them are best grown as pillar plants or for covering a bare greenhouse wall. Given good treatment and a rich soil, pot plants are, however, effective during the autumn months, and though they run somewhat tall are very useful for breaking up the flat surface of a group or bank of plants. To be seen at their best, young plants should be propagated for pot work each spring, and the method is to take off the tips of growing shoots about four inches long, inserting these 


\section{THE BOOK OF THE GREENHOUSE}

singly in three-inch pots in light, sandy soil, and putting them under a handlight in a warm house or on a hotbed, keeping them shaded from bright sunshine till they become rooted, which will be in the course of a fortnight or so after insertion. Remove then to the greenhouse benches and pot on in good soil, one-half fibrous loam, one-quarter each leaf mould and decayed manure, adding a fairly liberal amount of sand. Pot on into larger pots as often as they fill the previous ones with roots, continuing this till the end of June by which time they should fill pots varying in size from six inches to eight inches. When well rooted, give water freely and manure water occasionally. Abutilons like rather more heat than the ordinary greenhouse affords, and under its influence will continue to flower well into the winter months, but they may be grown entirely as greenhouse plants provided very little water is given during winter. They are liable to both green and white fly. Scale will also attack them; in fact almost all garden insect pests thrive on these plants when allowed the opportunity of doing so.

Begonias-tuberous.-For brilliancy of colouring and freedom in flowering combined, these plants have few equals. They are, also, essentially plants that may be grown under certain difficulties that would prevent the successful growth of some plants. For instance, they have no objection to a considerable amount of shade, and consequently may be grown in houses that have not quite the best aspect; also, being dwarf plants, they do not require much head room. They may be raised from seeds sown in carefully prepared pots of light sandy soil, using a large proportion of thoroughly decayed leaf mould. The seeds being very small should be sown on the surface instead of being buried. Sow in heat and shade, quite early in the year, for they are slow growing to begin with. Prick off, when big enough to handle, into small boxes or pans of light soil. Pot off 
when ready, using a tolerably rich soil containing plenty of humus and sand. If sufficient heat for seed raising is not to be had, a start should be made with dormant or semi-dormant tubers bought in early in April. Pot these up in pots that may vary in size from five inches to eight inches, according to the size of tuber. Stand in the greenhouse in a shady corner, and give little or no water till growth begins, after which, increase the supply gradually until by the time the pots are filled they will take an abundance, and should never be allowed to get dry. When growth and flowering cease in autumn, reduce the watering and keep quite dry through the winter in a frost-proof shed, leaving the tubers in the soil until potting time comes round again, or they may be shaken free from soil if dry, directly the top growth drops away, and stored in paper bags in a cupboard or cellar, but not close to the fireplace. When potting these developed tubers, put at once into the flowering pot, the tubers to be sunk just below the surface, with a dash of sand beneath each. Press the soil firmly with the fingers. Tubers showing several growths may be cut in two or more pieces, leaving some growths on each piece. The pieces should be allowed to dry in the sun, and the cut surfaces thickly powdered with lime or charcoal before potting.

Begonias-fibrous-rooted. - To these, the general treatment advised for the tuberous section will apply, but they should be propagated from cuttings of the new growths made in spring, and should never be dried off to the same extent, for if the roots were allowed to die off the plants would not recover. They like the warmth of the intermediate house in winter, and should then be kept fairly dry until new growth shows at the base. The would-be Begonia grower must keep a sharp lookout for a tiny species of thrips, which has the power of simply paralysing the plants by sucking its juices. It 


\section{THE BOOK OF THE GREENHOUSE}

is almost too small to be seen by the naked eye, but its presence is readily detected by the rusty marks it makes on leaves and stems. Directly these marks are seen, the house must be fumigated or vaporised with nicotine, and this should be repeated about three times on alternate evenings.

Cannas.-Handsome even as foliage plants, these have been much improved of late as regards freedom of flowering and size of flower. Some of the newer varieties are quite gorgeous and even startling in their daring mixtures of colour. They are easily grown, but require quite a rich and porous soil in which to develop at their best. The root stock should be divided in spring into pieces, each containing one or two crowns, and potted up in equal portions of good loam, sand, and decayed cow manure, using well drained pots, seven inches to ten inches, according to the size of clump, as Cannas require an abundance of water when growing. They may be grown in the cool house, but are grateful for more heat if feasible; and with increased heat should be increased humidity of atmosphere. They flower from July to November, according to the variety grown and the time of starting the clumps, for in this they are very accommodating. After flowering, reduce the water supply, and, when sufficiently dry, remove to a dry frost proof shed till potting time comes round again. In addition to being raised by division, plants may also be raised from seeds, which should be sown singly in small pots and plunged in a hot-bed to germinate, potting them on in the usual way as they fill their pots with roots. Before sowing the seeds, soak them in warm water for several hours, and then nick the outer casing through with a file, for unless this is done old seeds often fail to germinate. The only extra care Cannas need is to keep them out of draughts when growing. They are not much subject to insect pests. 
Carnations.-Two distinct types of Carnation, the Winter-flowering and the Malmaisons, are well suited for greenhouse work. The former are gaining in popularity and well deserve it. They should be propagated from cuttings or slips of the small side growths which form on the main stems early in spring, and may be struck in pots plunged in bottom heat so arranged that the tops can be kept fairly cool at the same time. When ready, pot off singly into small pots, place in a temperature of 60 deg., syringe freely, and keep them growing until mid-April when they may go into a cooler house. Some varieties require stopping, in which case the tops should be pinched out once or twice to make them bushy, but all operations of this sort should cease in June if flowers are wanted in winter, and at about that time the plants should be moved to a sunny spot in the open air, plunged in ashes and left there until the end of summer when they may be returned to the greenhouse and placed well up to the light. In a wet season, plants plunged outside suffer through the heavy rainfall and should be protected from this. Carnations delight in old pasture loam (which has been stacked for several months), with sand and powdered sea-shell or bone meal mixed in moderate quantities with it. They should never be over-potted, a shift of two sizes bigger should never be exceeded at a time. Good plants may be grown in six-inch pots. Watering must be done with great care as Carnations will not thrive with an excess of moisture at the roots. When the plants commence flowering, weak manure water may be given, or a little concentrated manure sprinkled now and then on the surface soil. Green fly is a troublesome pest that must be dealt with very frequently in order to keep clean plants. Malmaisons flower in the summer months when treated naturally, and will not thrive under artificial heat, from $45 \mathrm{deg}$. 
to 50 deg. being ample during winter. They should never be syringed, as this develops disease in the plants. They are propagated by layering the young shoots under glass during summer, and when these are well established in pots the tops may be pinched out. By stopping or pinching a few plants at a time, a successional flowering season may be had. A light house, where the plants may be brought near the glass and with provision made for slight shading in bright weather, will suit these plants. They are not to be recommended for growing among other plants.

Chrysanthemums.-For ordinary greenhouse decoration, these are best propagated early in spring, choosing cuttings from the base of last year's plants, not from the stems. Cutting these off near the base when about three inches long, insert them, either singly or in threes, in small pots of sandy loam and leaf mould. Take off only a few cuttings at a time, putting them at once in the cutting pots and watering well before they have time to flag. They may then be plunged in ashes up to the rims of the pots in a cold frame and kept close and shaded until rooted. Pot on when well rooted, putting the single cuttings into five-inch and the triplets into six-inch pots, returning them to the frame and increasing the ventilation day by day until the weather is fit for complete exposure. When they have grown about six inches high, nip out the tops to induce a bushy habit, repeating this process once or twice but not later than the end of June, and never pinching within a week, either before or after, of potting. The final potting into the flowering pots should be given in June or very early in July, and the soil at this potting should consist of two-thirds roughly broken fibrous loam and one-third decayed horse droppings, with some sand. Should the loam be heavy, use as a corrective some broken lime rubble or burnt earth in addition to the 
above. Ram the soil tolerably solid, as the plants like a firm rooting medium. At all times Chrysanthemums must be kept moist at the roots, and to effect this towards the autumn, when the pots are well filled with roots, it may be necessary to water two or three times a day. This love of water should be arranged for when potting, by leaving at least one and a half inches between the rim of the pot and the surface soil, so that sufficient to soak the ball may be given at each instalment. When flower buds have formed, feeding with manure may be commenced and continued until the flowers have opened. During the summer months, the plants must be stood outside in the open, so that the wood may be solid and ripen well. Late in September or early in October, according to locality, they must be brought into the greenhouse, which should be fully ventilated night and day. The removal will check the plants slightly, and it will be necessary to reduce the water supply for a few days until they become acclimatised to their new surroundings. As a safeguard against mildew, which frequently attacks the plants directly they are housed, if not before, they should be laid down and syringed all over with a solution of sulphide of potassium, using half an ounce to the gallon of soft water. Do not overcrowd the plants when housed, or indeed at any other time, for they must be allowed always to have plenty of air circulating round them. When flowering is over, cut the plants down to within six inches of the pots and remove them either to a cold frame, where they may be protected from severe frost, or to a light position in a cool greenhouse, giving for the time only a limited water supply and throwing them away after sufficient cuttings have been secured, for young plants are better than old ones for general purposes.

Crassulas.-The Crassulas or Kalosanthes, as they are sometimes called, are easily grown. To flower them 


\section{THE BOOK OF THE GREENHOUSE}

well, two important points in culture are always to give them the fullest possible amount of light, and to expose them fully in the open air during autumn as long as they are protected from actual frost, for this exposure gives the necessary check that "sets" the flower heads, and without it the plants, though remaining perfectly healthy, make only flowerless shoots. Big old plants that only flowered well in alternate years used to be much grown, but present day taste runs to smaller plants, and these must be raised from cuttings yearly. For this purpose, choose early in summer the tops of strong growths that do not promise to give flowers. Cut them off about four inches long, and, after stripping them of a few of the lower leaves, put them in a sunny place to dry for a day or two, then inserting them three or four round the edge of a five-inch pot which has been well drained and filled with a compost of one-half loam and one-sixth each of leaf mould, broken brick and sand. Give little or no water until they show signs of growth, and at no time must they be liberally supplied with water. If intended to flower the next summer, the points of the shoots should be allowed to grow away without being stopped. On the other hand, those intended to be grown into large plants should be stopped in the spring, and, when they have begun to branch out, potted on into larger pots. After flowering, in summer they may occupy a cold frame, gradually giving them full exposure to light and air but protecting from heavy rains, and in winter a shelf close to the glass in a cool greenhouse will be a suitable position. Never give more artificial heat than is necessary to keep out frost, for heat starts the plants into flowerless growth.

\section{II}

Francoas.-Francoa ramosa has earned for itself the appropriate popular name of Bridal Wreath. Its chief 
characteristic from a cultural point of view is its antipathy to anything like over watering, and it also resents being over potted. Indeed plants may be kept in good health for years without being repotted, and will give a good annual display of white wreaths with very little trouble in the way of culture, provided the above-mentioned points are remembered. It is hardy enough to stand frame culture all the year round, but, as frames are apt to be damp in winter, the best place for Francoas then is a dry shelf in the greenhouse. Young plants may be raised from seeds sown in spring in sandy soil and placed in an intermediate temperature. Pot off into small pots when fit to handle, and again into four and a half inch pots, which will be big enough for the first year, a furher potting taking place in the following spring. They may also be raised in a cold frame by sowing seeds in the autumn as soon as they ripen on the old plants, and this is the better way for those who cannot give heat in spring; indeed I prefer this method in any case, providing that a light and drip-proof corner can be found for the seed pan in winter. Francoas thrive in a compost of loam, leaf mould and sand, using the latter very freely, and potting very firmly.

Fuchsias.-The Fuchsia, when well grown, is a rather gross feeder and should be given good rich soil when potting, which should be done in the case of old plants just when new growth begins to push out after being pruned in spring, at which time no harm will be done by reducing the size of the old ball of soil somewhat, so as to give room for new soil without much increasing the size of pot. A mixture of half loam, one-quarter each of decayed cow manure and leaf mould with sufficient sand to keep the whole of an open nature will suit well. Pot with moderate firmness, syringe freely two or three times a day, giving very little water at the roots until the plant 


\section{THE BOOK OF THE GREENHOUSE}

is seen to be growing freely, and shade from bright sunshine. Fuchsias delight in a house which is shut up early in the afternoon and heavily syringed daily, up to the time they show their flowers. Badly shaped or very thin plants may have their shoots pinched at the tips two or three times during the early summer, but this pinching must cease about seven weeks before they are expected to flower.

To raise new plants, those who cannot command strong heat early in the year, should make cuttings of growing shoots without flower-buds in July or August, and strike these in cutting-pots in a cold frame, moving them to the greenhouse shelf when rooted, and keeping them slowly growing on all winter, potting them off early in spring and again later on when well rooted. It will be found necessary to repot again, this time into the flowering-pots, a few weeks later, as it is not advisable to give the plants a large quantity of new soil at one time. Pick off all flower-buds as they show, until the plants are large enough for flowering, when they should be given clear manure water at each alternate watering and never allowed to become dry at the root. If the plants are to be kept over winter, reduce the water supply when they finish flowering, and, when the soil is quite dry, store the plants in a frost proof shed or cellar until spring. If the wood shows signs of shrivelling during winter, spray it over occasionally with water but keep the roots dry. About the end of March, bring again to the greenhouse and prune into shape, cutting away all small and unripe wood. As a general rule, it may be said that the harder the plants are pruned, providing the foundation of a good shape is preserved, the better they will break and grow away again. For a few days after pruning, give no water, and very little will be needed until growth is well in progress. Fuchsias are subject to many insect pests, and especially so in houses 


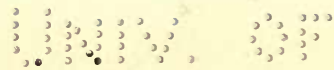

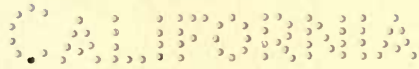

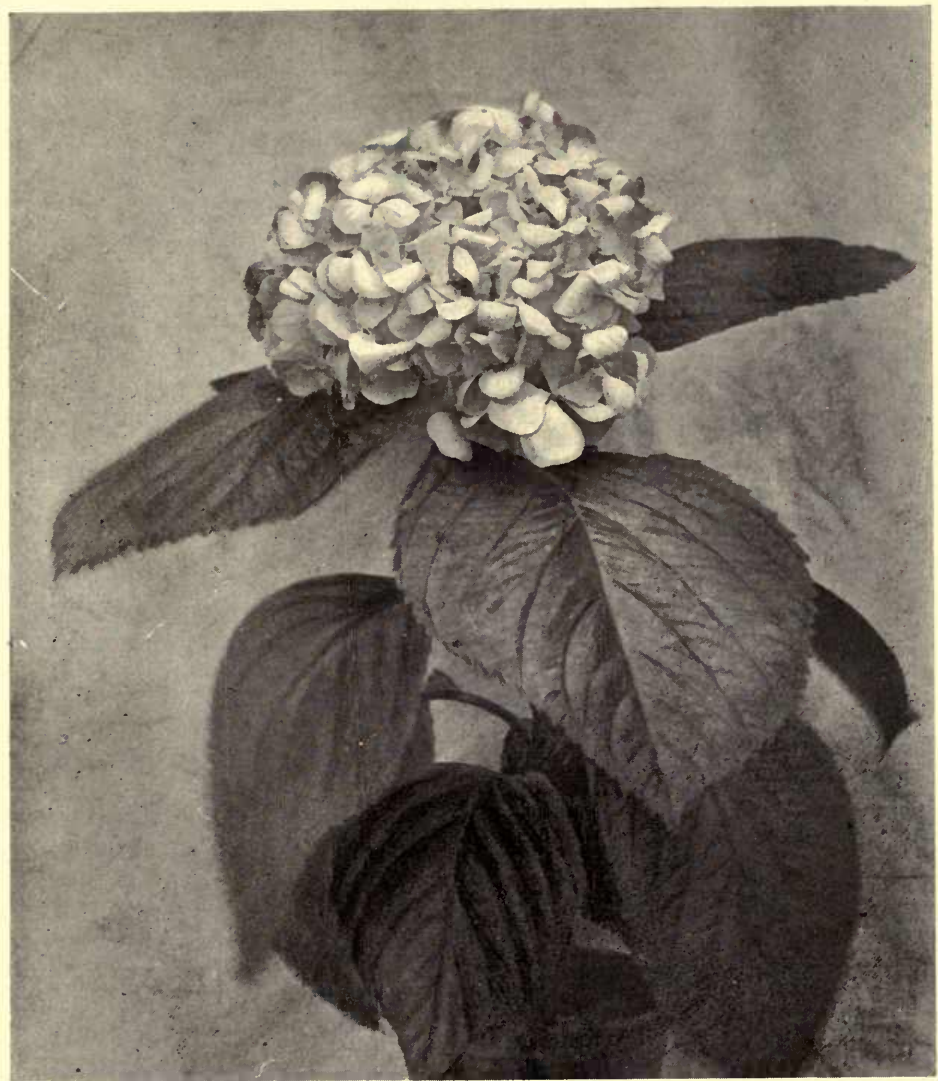

HYDRANGEA HORTENSIS 


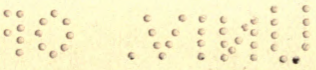

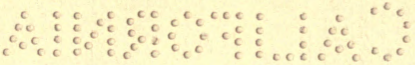


deficient in atmospheric moisture. If allowed to become infested with insects, they can never flower well or be in any way attractive.

Hydrangeas. - A few of the Hydrangeas make excellent pot plants. They like a good, loamy soil, enriched with about one-third of decayed manure, and during the growing season they enjoy plenty of water. Old plants should have all small shoots cut out entirely, during the winter or spring, leaving the stronger ones intact, as these will flower from the tips. Any strong new shoots showing at the base should be encouraged. On the number of strong well ripened shoots will depend the quantity of flowers produced. The white flowered $H$. paniculata bears hard pruning, as it flowers well from growths of the current year. $H$. bortensis, the common sort, may be grown in a small form with one big head of flower to a plant under the following treatment, and this will indicate sufficiently the general treatment required by either old or young plants. In spring, cuttings should be made of strong young growths, that are not showing flower, and struck in a close frame putting only one cutting in a pot. When rooted, pot into five-inch pots and grow on freely, giving full exposure to the young plants towards the autumn. When the leaves drop, put the plants in a cool greenhouse and keep them dry at the roots all winter, resuming watering when growth commences in spring. After flowering, these plants may be kept to form bushy specimens; and, to encourage a good habit, they should be cut down almost close to the ground and allowed to break into growth from the bottoms. Such plants should be potted into larger pots early in spring.

Pelargoniums (Show).-Pelargoniums may be roughly divided into two sections, viz. Show and Zonal, each of distinct value for the greenhouse. They each con- 


\section{THE BOOK OF THE GREENHOUSE}

tain sub-sections, the treatment of which does not require special notice. Show Pelargoniums are very useful for flowering in the early summer. Old plants may be grown on year after year, the treatment being to remove the plants from the greenhouse directly they have flowered, putting them in a sunny spot in the open air and lessening the water supply gradually until, by the end of July, the wood is well ripened and the roots are quite dry. Cut back almost close to the base of the young wood, and stand in a frame so that rain may be kept off the plants, but expose to all fine weather. Sprinkle the stems daily, but do not water the soil until new shoots are appearing freely, and even then in only sufficient quantity to keep them plump. When an inch of new growth has been made, turn the plants out of the pots, cut away the longest roots and reduce the ball of soil to about half its size, then repotting firmly in a smaller pot that only allows a little room for new soil. The soil used should be fibrous loam that has been stacked for some months, and this should be pulled into fairly small pieces and mixed with about onefourth of well decayed manure and a good sprinkling of silver sand. Return the plants to the frame and keep them there with their heads close to the glass, water carefully, and afford only the very lightest of shading in bright weather. Remove to a light shelf in the greenhouse when late autumn fogs set in, and keep the roots on the dry side. In December, pot into the flowering pots, which need not be over large, and which must not in any case exceed by more than two sizes those in which they have been growing. Most of these plants make more shoots than are required after pruning, and some of the weaker ones should be rubbed off, but any that do not make sufficient to begin with will do so if their points are pinched out in February; this, of course, somewhat 
retarding the flowering season. Plenty of ventilation is necessary, as the plants do not like a close atmosphere, neither will they stand much artificial heat. When the buds show, give weak manure-water occasionally. Propagate either in summer from half ripened shoots with their points intact, or at pruning time from ripened shoots the points of which have been cut out. Pelargoniums of this section are very much subject to attacks from green fly and must be often fumigated or syringed with tobacco water.

Pelargoniums (Zonale). - The use of these for greenhouses in summer is well known, but what I wish to point out here is their extreme value as winter flowering plants. Take cuttings in February, striking these singly in three-inch pots, the cutting pots to be placed on a sunny shelf so that the cuttings become well hardened from the first. When well struck and growing, pinch out the points, which will cause new shoots to form, and, when these are an inch or two long, pot the plants into four and a half inch pots, ramming the soil firmly. Place in a garden frame exposed to full sun. About the end of June, pot again into six-inch pots, using a very sandy and fibrous loam lightened with a little decayed horse droppings. Keep all flowers pinched off during the summer, or say till the middle of September, then remove to a greenhouse with a dry atmosphere and a minimum temperature of $50 \mathrm{deg}$. to $55 \mathrm{deg}$., in which they will flower splendidly during the greater part of the winter. They should be grown close up to the light at all times and more especially so when flowering. All varieties are not equally free winter bloomers, but any nurseryman would suggest a good set of varieties for the purpose.

Richardia Aetbiopica. - This plant is popularly known as the White Arum or Calla Lily. Though a native of the swamp, it requires, when used for pot work, a season of 
rest, and it is neglect of this that often leads to failure. Another point to remember is that it is a gross feeder, enjoying rich soil and manure without which it cannot make tubers strong enough to flower well. When the flowering season is over, give but little water for a couple of months, and put the plants in the open air early in June. When the growth is well matured, turn the plants out of their pots, dividing the tubers and retaining the stronger ones for repotting. A portion of the stock may be potted at once in loam, manure and sand, giving free drainage to carry off the large quantity of water required when growing freely. Stand in a cool frame or out of doors on a bed of ashes and remove to the greenhouse before frosty nights set in. This batch should flower early, and will be succeeded by the second portion which should be planted out in a trench partly filled with manure and soil. In this trench the plants will grow very strongly if kept well watered, as they should be, and early in September they must be lifted carefully and potted in pots large enough to contain most of the roots and sufficient soil to prevent them from feeling much check. For a few days after being potted and well watered in, they should be kept in a close frame and shaded, removing them afterwards to the greenhouse benches. The danger in growing under this system lies in keeping them growing too long in the trench before potting, for they then become unwieldy and do not take kindly to the pots. From the time that flowering commences, feed well with manure water, and never let the plants get at all dry when growing. Richardias are very subject to green fly, but must at all cost be kept free from this pest which will otherwise soon spoil all the spathes.

Roses.-A batch of well-grown pot roses makes a charming addition to any collection of greenhouse plants, and they can be easily grown and prepared for the purpose. Contrary to the usual practice, I would 
strongly advise all those who have only room for a few plants to let these be of the Hybrid Perpetual class and to eschew the Tea Roses charming as they are, for the former are not so subject to mildew, the bane of pot roses under glass, and, if they are not quite so free flowering, their flowers have more substance and lasting power. All varieties are not equally suitable for pots, but there are many in each class that are suitable, and one has a fairly wide choice in almost any colour that may be preferred. Before attempting to flower these roses under glass, it is necessary that good, strong plants shall have been for a season established in their pots. They may be safely kept in the open garden until they are wanted to commence growth, provided the pots are plunged to the rims in ashes. On bringing them under glass, the first thing to be done will be to cut out bodily all growths less in size than an ordinary cedar pencil, and to shorten the strong ones to within two or three buds of their junction with the older wood which forms the frame of the plant. Until the cuts dry over, keep the plants cool, after which they may be forced in a temperature of about $55 \mathrm{deg}$., rising gradually to $65 \mathrm{deg}$., or brought on slowly in the ordinary temperature of the greenhouse, but in any case they should be jealously guarded against draught at all times, very little air being given to the earliest batch of plants. Keep in the greenhouse until it is safe to move the plants outside, attending closely to their needs in the way of watering and giving manure water occasionally, for on the production of strong wood depends mainly the success for another year. To this end it is wise to rub out shoots that do not promise to be strong. Choose a sunny spot in the open for the summer quarters so that the growth may be well ripened. Early in autumn, any potting that may be necessary should be done, using rich turfy loam, a little sand, or 


\section{THE BOOK OF THE GREENHOUSE}

lime rubble, and a sprinkling of crushed bone. Pot firmly and in well-drained pots. Well managed roses will go on in the same pots for some years, provided that much of the old soil is removed and replaced by fresh material each autumn, so that an annual repotting is unnecessary when they reach eight-inch and nine-inch pots. Roses are well known to be subject to green fly out of doors. Both this troublesome pest, and red spider also, will attack them under glass and must be given no quarter. The last named insect only troubles plants that have been grown in too dry an atmosphere.

Salvia splendens.-Other Salvias than this are good greenhouse plants, but the best form ( $S$. splendens grandiflora) of the one named is by far the finest of all for pot work and gives a grand display of brilliant colour late in autumn, when brightness is most needed. It may be propagated in spring either from young shoots made into cuttings and struck on a hot-bed, or from seeds saved from a good plant and raised in heat. The young plants are quick growing and must be kept on the move by repotting as often as necessary, using a mixture in which loam forms one-half, the other half being composed of equal portions of leaf mould, decayed animal manure, and sand. The final sized pots may be anything from eight inches to eleven inches according to the size of plant required. When danger from frost is over, put the plants out of doors in a semi-shaded position, not overhung by trees, and, when they have grown about two feet high, pinch out the tops and allow all the side branches to develop at will. Before frost comes, remove again to the greenhouse where they are to flower. A temperature of $50 \mathrm{deg}$. to $55 \mathrm{deg}$. will hold them in flower for a long while, and, if the proper variety has been grown, the calyces will remain bright for weeks after the flowers have dropped. This plant is not much subject to insects, but red spider sometimes gets on plants allowed to become too dry 


\section{MISCELLANEOUS PLANTS}

or pot-bound, and to prevent this they should be well syringed every evening while in the open air. Shade should not be given except in summer, and must not be overdone then; indeed all that is necessary in this way is to keep the pots cool and to prevent the plants from flowering too early. 


\section{CHAPTER VIII}

\section{Foliage Plants for the Greenhouse}

Although good flowering plants are such charming subjects for the greenhouse during their flowering period, there is another section, perennial in its charms, consisting of plants which are grown entirely for their beauty of form and of foliage. These are either noiiflowering or they bear insignificant flowers that are not valued. Most of the plants mentioned in this chapter are of very easy culture, and as they do not require the ripening which is so essential to most flowering plants every year, and are content with only a moderate amount of light, they will be found suitable for badly-placed houses in which it is found difficult to grow flowers. The majority of these plants like a temperature a little higher than that given to the cool greenhouse, less ventilation, more humidity of atmosphere and shade.

Ferns.-Chief among foliage plants come the ferns, and few need be told of the infinite variety of form or of the exquisite tints and shades which are to be found among this class. One cannot here go into detail as to the management of each species, but, fortunately, the chief points in greenhouse fern culture do not vary greatly. One of the essentials is a good supply of water, and, to enable the soil to withstand the effects of frequent watering without being turned sour, all pots or other receptacles should be exceptionally well drained, and the soil itself made extremely porous. $\mathrm{A}_{80}$ frequent cause of disaster to ferns of delicate 


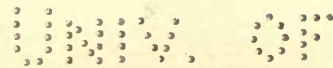

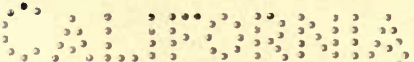

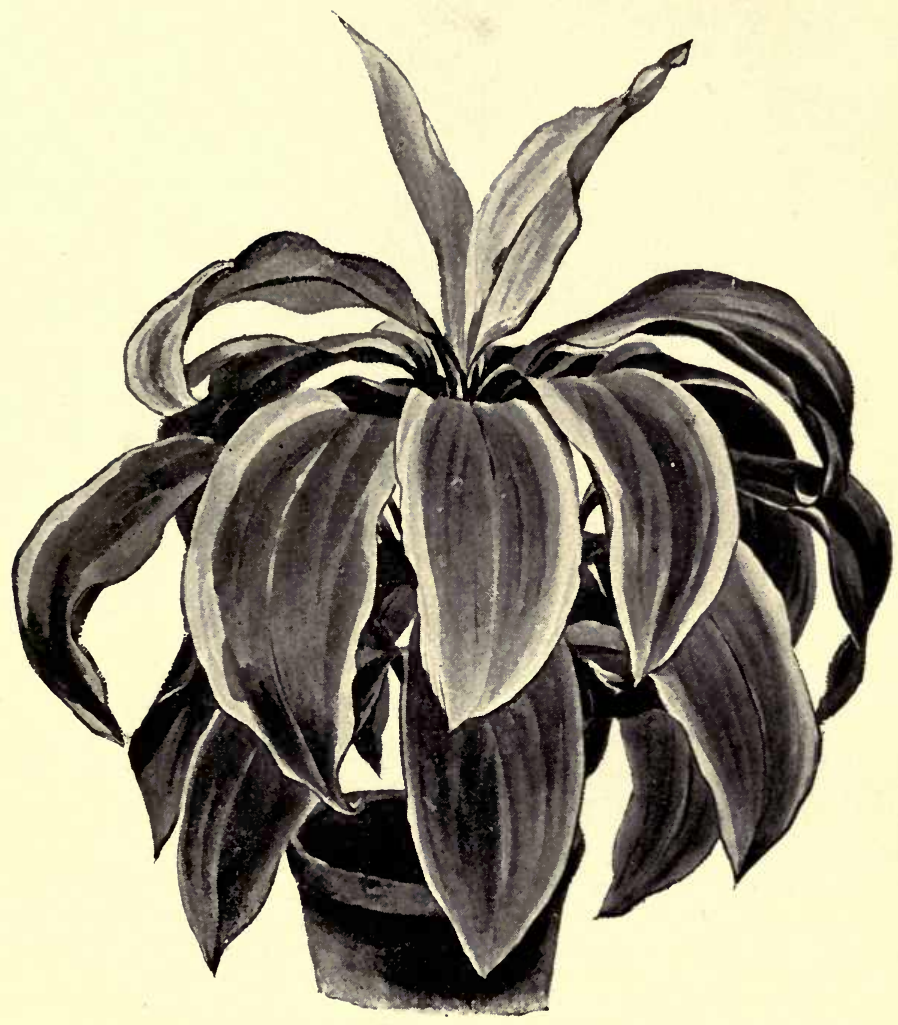

DRACAENA-THE SIRDAR 


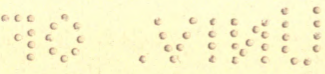

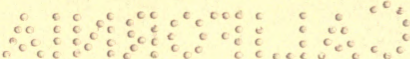


root action is over-potting and using too deep a body of soil in the pots. A good depth of soil may be suitable for some of the strong growing Pterises, but for delicate Adiantums and all ferns that spread themselves by creeping rhizomes it is especially wrong to pot or plant in a big body of soil, for with these the soil is merely a medium through which the necessary moisture is conducted to the plants, and if too much is used it is soon rendered unfit to perform its office and the roots die out and are not replaced. As a proof of this, one may frequently find in ferneries plants refusing to grow in elaborately made but too capacious pockets, while fine plants of the same varieties may be found growing well out of the merest crevices into which a rhizome may have chanced to escape, or a spore to have germinated, providing the position is such as to allow of a bountiful water supply.

All potting operations should be carried out in spring just as the new fronds of the year are about to appear, for at this time the roots are fully active or will soon become so, and consequently the new soil is the sooner filled with roots. At the same time, if increase in number is desired, the tufted ferns may be split up, taking care that each division is well provided with crowns and with roots, so that each will soon make a good and shapely plant.

The soil used in potting may be half fibrous loam, broken up as roughly as it can be used, with leaf mould and peat in equal proportions, and with the whole should be freely incorporated finely-broken brick, charcoal, or some other porous material, and a liberal amount of silver sand.

Most greenhouse ferns may be raised from spores, the operation being a somewhat delicate one. Shallow pans should be half filled with crocks, and on these should be placed a very thin layer of the more fibrous and lumpy por- 


\section{THE BOOK OF THE GREENHOUSE}

tions of the potting soil, pressing this flat, watering well, and then shaking over the surface a few fronds of the desired varieties which have ripe spores, i.e., the brown powdery substance found round the edges or spotted over the under sides of the fronds. The pans should then be placed in a damp and shady corner of the greenhouse and covered with sheets of glass. They may be watered by partly immersing the pan, taking care not to let the water rise to the level of the surface; or perhaps a better way is to stand the pan, as soon as sown, in another pan which will hold water, and to keep this partly filled so that absorption is constantly going on, but if this method is adopted see that the water is kept sweet by constant renewal. Rhizomatous ferns may be increased by securing a lump of soil to the rhizome near the end and severing this portion when roots have formed. A few ferns form young plants on the old fronds. Such may be easily detached and potted up in the usual way.

Palms.-Next to ferns, the palms are perhaps the most desired of ornamental foliage plants, and many of these may be grown in quite a moderate temperature, provided other conditions are favourable. Few plants are happier under deep shade and in a very humid atmosphere during at least eight months of the year. Plants grown under these conditions require very small pots in proportion to their size, very seldom need repotting, and do not need nearly so large a quantity of water at the root as is generally given, provided that they get a good amount of overhead syringing. I do not mean to infer by this that the roots should ever be allowed to get dry, as this would be harmful, but would insist that the moisture shall be ever present in the atmosphere and on the externals of the plants, rather than poured in large bodies through the soil. When potting is necessary, it should be carried out in spring, and the soil used should be similar to that recommended 
for ferns and should be used in a lumpy condition, for the presence of much fine soil is wrong. The plants should be transferred to the smallest pots that will constitute what gardeners know as a "shift," i.e., allowing just room for a little new soil all round the ball. No soil should be put above the "collars" of the plants, as they like best to rest on and not in the soil. So long as the plants remain healthy looking and good in colour, I would recommend that no repotting be done. This period will of course vary in length, according to the temperature kept up and the species which are grown.

Palms may easily be raised from seeds sown in a fairly high temperature as soon as received, but for most people it is best to buy small plants from the nurseries.

Aspidistras. - The Aspidistras are frequently given the popular name of Parlour Palms, indicative of their ability to bear the rough usage and neglect often met with by plants grown in dwelling-houses, and they well deserve the name. There are both green and variegated forms, the latter being rather more delicate, or at least more prone to lose portions of its variegated leaves, and to run back to the green type. This can only be prevented by cutting away the green leaves as they form, and by taking a little extra care to keep the plants out of the way of cold draught on the one hand and fire heat on the other, as either is calculated to kill the white tips and edges of the leaves. The simple culture necessary is to give rather a large supply of water during the greater part of the year and a little less in winter. Sponge the leaves frequently and dry them, especially those of the variegated form, before leaving them. Pot in spring when the plants become crowded with growths, and, if desired, divide them at the same time to increase stock. A good potting mixture is loam and leaf mould or peat in equal proportions with a liberal addition of sand, using plenty of drainage. 


\section{THE BOOK OF THE GREENHOUSE}

Begonias.-Begonias of the Rex type are easily grown in pots of loam, peat and sand. They offer no difficulties of culture, provided they get a fairly high temperature, shade, and a liberal water supply during the summer. The best method of propagation is the curious one of raising several young plants from a single leaf. It is carried out by filling a well-drained pan with compost as for potting, sprinkling over this a further layer of sand, and then cutting a fully developed leaf with an inch or two of stem attached, imbedding the stem in the soil so that the leaf may lie flat on the surface, then scoring across the larger ribs of the leaf in various places. Sprinkle over each cut sufficient sand to weigh it flat down on to the soil, put into a warm house, and in the course of a few weeks young plants will have sprung from each severed mid-rib; these may be detached and potted singly after they have formed a few roots. Perhaps a simpler method of propagation is to take off the points of growing shoots with two or three inches of stem, putting each singly in a small pot. Only just sufficient water to prevent extreme flagging should be given until the cuttings have taken root.

Cordylines and Draccenas. - For gardening purposes these may be classed together, the culture of the greenhouse species being identical. They make handsome plants in rather small pots and are indeed very useful for many purposes. Good loam, with peat or leaf mould and sand, is a suitable compost. Propagation is carried out in various ways. The tops may be converted into cuttings, but these require a hot and close place in which to take root quickly, and the better way is to take off a ring of bark just below the lowest leaves, or to make, with a sharp knife upward, sloping incisions on opposite sides of the stem, binding the latter with a big bunch of moss, and keeping this moistened until roots form, then separating the head below the moss and 


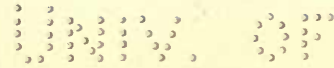

$$
\begin{aligned}
& \therefore \quad \therefore ;
\end{aligned}
$$

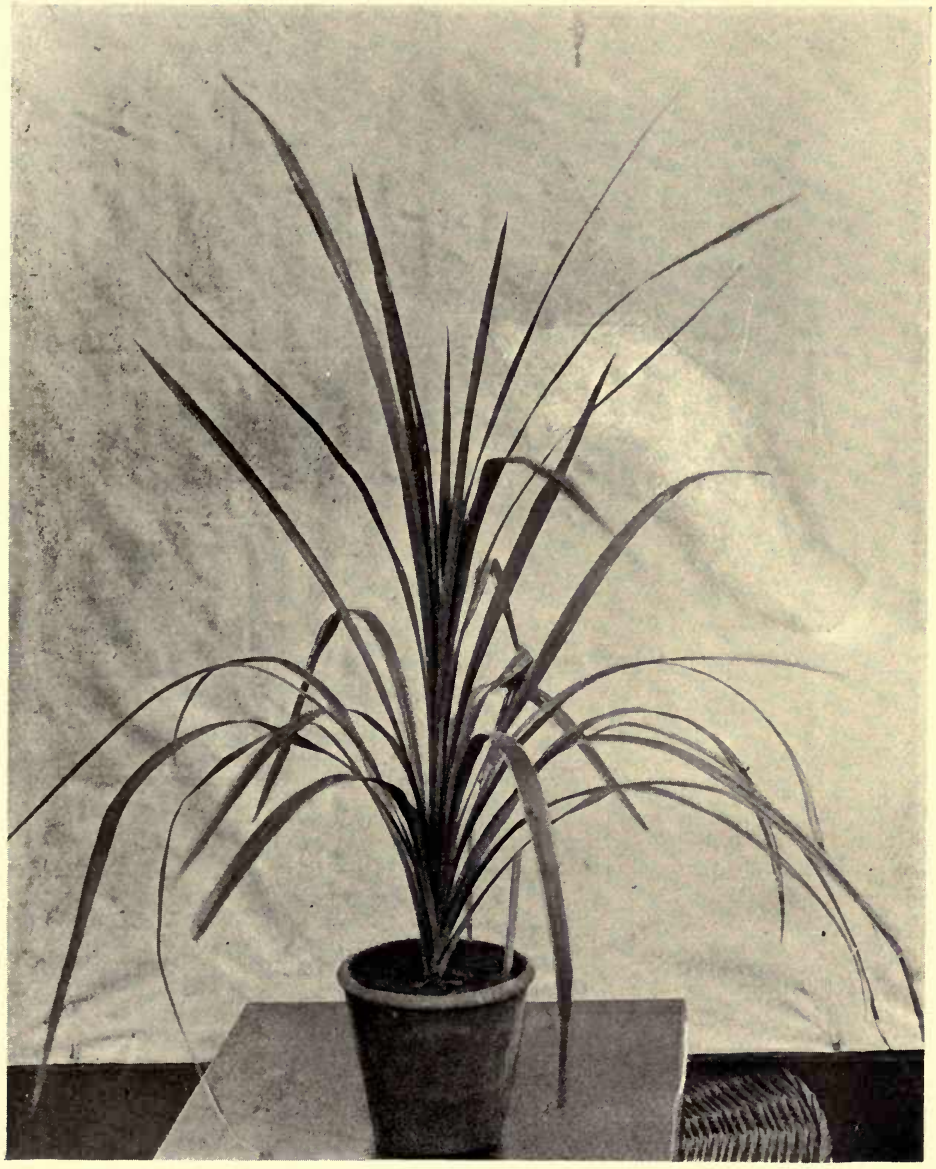

CORDYLINE INDIVISA 


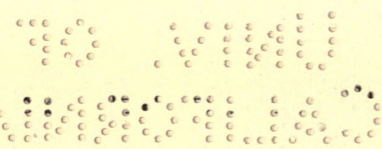


potting up in the usual way. As an alternative to the bunch of moss, a good plan is to split a small flower pot in half and enclose with it the stem where the ring or the incisions have been made, fix it fast and fill up with suitable soil which must be kept soft enough to induce root action. This is the safest mode of all, but pots are rather troublesome to split so that the halves may fit together again nicely. The above methods are used to obtain grown plants at once, but young stock may be raised by cutting into short lengths and splitting the old stems. The cuttings thus made may be laid flat in pans of soil or cocoanut fibre and slightly buried, and in a few weeks roots will form and buds will grow that eventually form plants. From the fleshy nodes or "toes" of the root stock, too, young plants can be obtained by adopting the same method except as regards splitting. Cordylines may, also, be raised from seeds quite easily, if the latter are obtainable in good condition. The seedlings make handsome little plants, useful for many purposes. $C$. australis is one of the easiest to obtain in this way, as seeds of this often ripen on big plants that grow outside in the warmer parts of England.

Fatsia japonica.-This plant is perhaps better known as Aralia Sieboldi. Its large, glossy, palmate leaves are always admired in a good specimen. Being almost hardy, this is a suitable plant for the cool greenhouse. It grows well in any ordinary mixture of soil suitable for greenhouse plants and is not fastidious in its requirements, but should always be kept in vigorous health by careful attention to watering, which must be ample during the summer, and to keeping the leaves clean by sponging frequently. To propagate the variegated forms of this plant, portions of the stem of an old plant must be cut up into short lengths and inserted as cuttings, keeping them in a rather close atmosphere 


\section{THE BOOK OF THE GREENHOUSE}

until rooted. The green form is best raised from seeds sown in the ordinary way and placed in an intermediate temperature to germinate. Many people fail to raise seedlings owing to the fact that the seeds they get have lost their germinating power, as they do after a very few months of storing. Seeds ripen with us in April and, if then sown almost directly, every seed will germinate. The prevailing custom of ordering in all seeds quite early in the year prevents the seedsmen from supplying new seeds of this plant. Order in April and insist on having new seeds.

Ficus elastica. - The Indiarubber plant is a universal favourite. To be seen at its best for greenhouse purposes and for room decoration, it should be in the form of a single-stemmed plant, clothed from bottom to top with well developed leaves. Directly a plant gets leggy, it should be treated as advised for the tops of Cordylines, i.e., induced to root just below the lowest leaf into a bunch of moss, or a split pot, before cutting it away from the parent stem. In making the incisions from which roots will form cut into the stem to a depth of about onethird of its diameter on either side, leaving the remaining portion to draw up sap for the support of the top until it becomes self-supporting, when it may be cut away and kept shaded and well syringed for a few days. In greenhouses with only a moderate amount of heat, this way of propagating should be carried out early in spring, so that the plants may be repotted and well rooted into the new soil before winter. Fibrous sandy loam with about a third of leaf mould is a suitable compost for the Ficus, and the pots need not be large in proportion to the plants. The leaves should be frequently sponged over with soft water, and every care taken to guard them from injury either through rough treatment or from scorching. The roots should be kept well watered and 


\section{FOLIAGE PLANTS FOR GREENHOUSE 87}

never allowed to become quite dry during the summer, but in winter only a limited supply should be given, the aim being to keep the plant both from flagging and from growing, for new leaves made during winter in a low temperature are certain to be defective and will spoil the symmetry of the specimen. 


\section{CHAPTER IX}

\section{Little Town Greenhouse}

ThE possibilities of the Town Greenhouse depend, in addition to its construction and aspect, very largely on the size and especially on the nature of the industries of the town itself. Where the air is pure and wholesome, the town grower of plants has, with certain limitations, almost as much chance of growing good plants as his peer in the country, but in operative districts with air full of smoke or vitiated with chemicals, the grower's lot is not a happy one, and, unless he is endowed with more than the normal amount of patience and perseverance, the contents of his greenhouse will generally be found poor in quality and very deficient in the way of variety. The owner of the little town greenhouse is generally a person with business engagements that prevent the constant attention required by many plants, and this largely discounts the probabilities of success. Such an one should not attempt to fill his house or houses with a mixture of plants of diverse nature, as more pleasure would be gained in taking up one class of plant-and that one not too fastidious in its requirements. Take, for instance, the Cacti and other succulent plants, and we find a most interesting group, the study of which is fascinating, the labour attached to its cultivation light, and that will bear with impunity neglect which would be absolutely fatal to very many of the plants treated of in this little work. It must not be inferred from this that no skill is required in their culture: on the contrary 


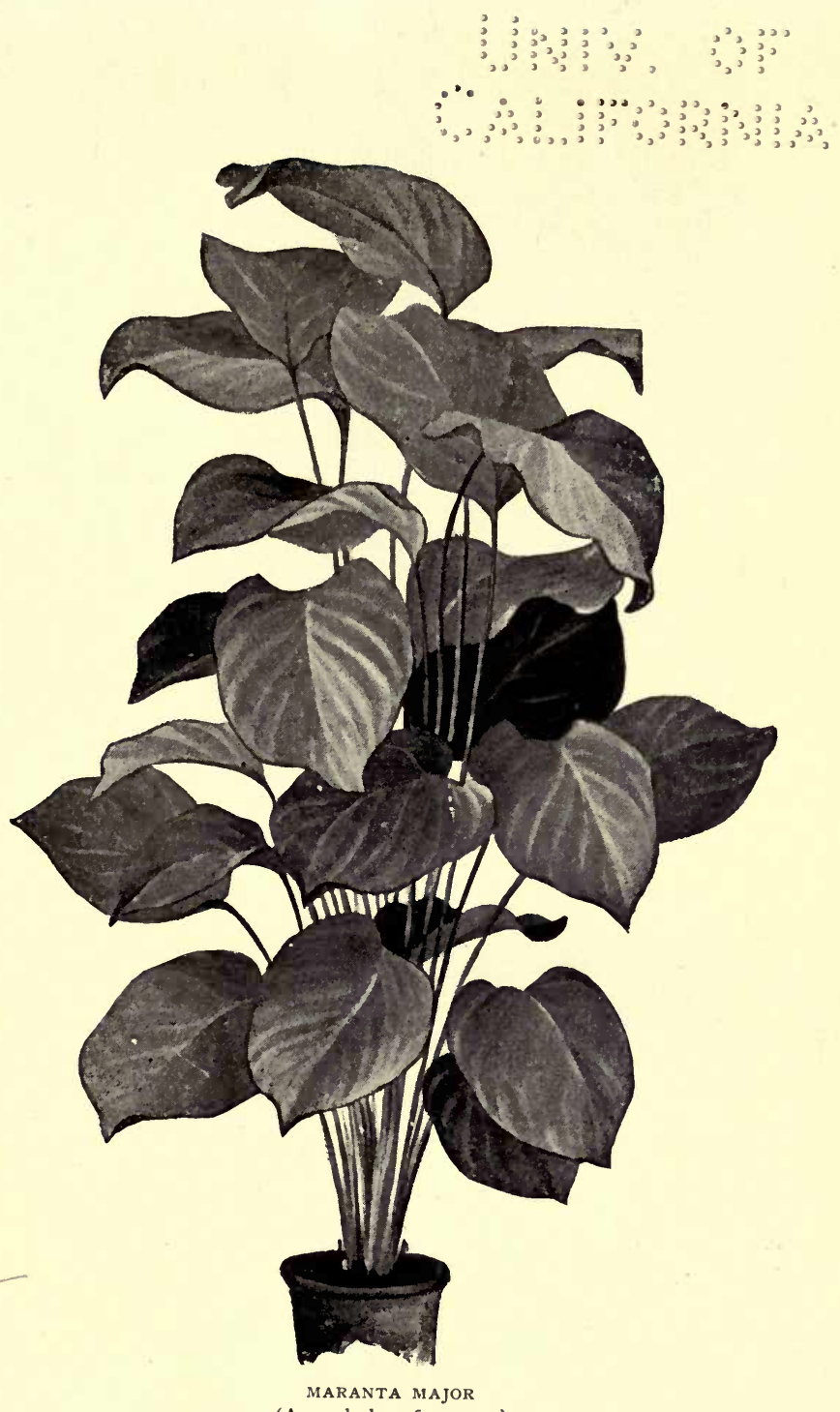

(A good plant for towns) 


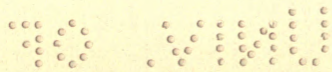

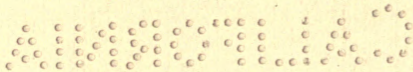


there is much to learn as to their successful management, and many chapters might be written on them alone, but what I wish to convey about them is that their needs are not constantly in evidence; sunshine and cloud may succeed each other rapidly without doing them harm, and a few hours' neglect in the matter of watering may be viewed with equanimity, for most cactaceous plants will thrive on a very limited water supply; indeed, this is a matter that requires study, for it is far easier to give them too much than it is to refrain at the proper time. Again we will suppose that the greenhouse has a bad aspect, i.e., does not get a full amount of daylight or sunlight; the owner will in such a case be wise in devoting his house to ferns and other plants which like shade, making no attempt to grow flowers, except possibly a few imported bulbs for spring effect, or Streptocarpus, or any of the few other flowering plants which do really well in shady houses.

Injudicious mixing of plants spells failure in the town, and also indeed in the country greenhouse, and must be avoided by all who wish to grow their plants well. As an object lesson, I would advise any owner of a greenhouse who wishes to grow many mixed species of plants in the same house to go first to one of our big town nurseries and note how the plants are distributed in them. It will be found that each house used for growing plants contains but one class of occupant. Probably the most attractive house in the nursery, viz., the "Show" house, will contain quite a mixture of plants, but these are only brought together for show purposes and soon go back again to their proper quarters, for no nurseryman would dream of attempting to grow them all together. Such Show houses are delusive in the extreme to those who do not understand the subject, and fill the mind with envy of the means by which such a display is brought about, but, when one looks at the matter with some knowledge 


\section{THE BOOK OF THE GREENHOUSE}

of the subject, one plainly sees the impossibility of emulating such success except under the similar conditions of having many other houses from which to draw the plants needed to keep the Show house gay. By dealing rather largely with varieties of a few species that may be well grown together, one gets the pleasures of comparison and of noting the differences which add so much to the attractions of the flowers. Through this channel comes the love which one gets from one's plants, a very different feeling from the pride of having a socalled good "collection" of plants.

Many dwellers in towns find great pleasure in the cultivation of Orchids, and, as there are many of these quaint and beautiful plants which may be grown in a cool house, when their requirements are understood and catered for, and as fresh importations are being frequently and cheaply sold, there is little to prevent any one who has a greenhouse from attempting their culture. A point in their favour for small houses, with limited accommodation, is that they grow but slowly and are not constantly becoming in need of more room either as regards the roots or the top-growth. Orchids require special treatment of their own, but are not by any means difficult plants when once the details as to temperatures, the principles of watering, application of shade and ventilation are mastered. Many of these plants gather most of their moisture through their aerial roots, and this has of course to be provided by the atmosphere of the house. Many of them, too, have a fairly long resting season during which the supply of water must be strictly limited with a view of preventing out of season growth which would be calculated to throw the plants out of gear, and this in turn would prevent the production of good flowering growths. Strong root growth made at the proper season lays the foundation for good health and successful 
results in the way of flowers. Plant pests such as wood-lice and slugs are ever on the alert to attack and devour the fleshy roots as they form, and must be circumvented by constant watching for and killing. Most of the plants mentioned in this book are good for town culture providing the surroundings are not too much shut off from fresh air and light. For badly placed houses it would be wise to eschew most of the hardwooded plants and to use more freely those which are mentioned in the chapter on foliage plants, as these are not dependent on being well ripened each year. Azaleas flower well in towns but are not to be depended on to ripen wood and form good flowering buds each year.

Pelargoniums are liable to lose their flowers during foggy weather, and it would be useless to attempt growing the Zonale section for winter flowering in the urban districts of a big town where fogs are prevalent, indeed fog is the worst element with which the wouldbe town gardener has to contend, for the danger of admitting fog through the ventilators adds much to the difficulties of affording proper ventilation. During long continued foggy weather the flowers of many plants will succumb in spite of all care. All ventilation given at such times should be at the apex of the house and the atmosphere within must be made sufficiently buoyant by the use of fire heat to keep the fog at bay as much as possible. 


\section{CHAPTER $\mathbf{X}$}

\section{Conclusion}

Having given in the foregoing chapters some idea of the correct treatment of many plants from which selections may be made that will,-if judiciously treated and catered for, give a more or less brilliant display of flowers in the well-appointed greenhouse all the year round, I should like in conclusion to say a few words as to the possibilities of the cold or inadequately heated house. There are many plant lovers with limited means or accommodation, who struggle on, trying with infinite pains to grow the ordinary greenhouse plants and failing for want of means to keep up the requisite heat in winter. To all so placed I would suggest the growing of plants that only require sufficient heating power to exclude actual frost and to add to these for the sake of variety some of our hardy plants that are suited for growing in pots. The Primula family alone, including as it does the Auricula, loved, and almost worshipped, by the florist of the past generation, is rich in species which do admirably in the cold greenhouse, many being happier and more at home under glass than they are in the open garden. Hardy bulbs of almost all kinds do well in pots for a season at least, and Anemones, Wallflowers, Stocks, Pinks, Phloxes, Columbines, Forgetme-nots, Campanulas, Pansies, Christmas and Lenten Roses, Michaelmas Daisies, hardy annuals of sorts, and a host of other things may be pressed into the service. All these render a good account of themselves 
in the greenhouse which has its share of sunlight, while, for the badly placed or shaded house, there are Ferns without stint. Houses filled with such things may be maintained at very little cost, and the pleasure derived from them is great. There are no great worries in the way of heating arrangements or attention, provided that the owner rigorously excludes all very tender plants, or grows these only through the summer months and gets a fresh supply each year. Ambition to keep such things along with others that need only cool treatment often leads to all-round failure, and he only is happy who, having a proper estimate of his environment, does not attempt too much. 



\section{Handbooks of Practical Gardening}

\section{EDITED BY HARRY ROBERTS}

\section{Price 2s. 6d. net each. Crown 8vo. Illustrated.}

THE BOOK OF ASPARAGUS. With sections on Celery, Salsify, Scorzonera, and Seakale; and a chapter on their cooking and preparation for the table. By CHARLES ILOTT, F.R.H.S., Lecturer on Horticulture to the Cornwall County Council.

"The work of a specialist. Mr Ilott gives us-for a matter of half-acrown-the ripe experience of a life-time."-Speaker.

THE BOOK OF THE GREENHOUSE. By J. C. TALLACK, F.R.H.S., Head Gardener at Shipley Hall.

"A serviceable handbook for the practical gardener, written with ex. ceptional knowledge of horticultural work."-Outlook.

THE BOOK OF THE GRAPE. With a chapter on the History and Decorative Value of the Vines. By H. W. WARD, F.R.H.S., late Head Gardener at Longford Castle.

"A mine of useful information." -St James's Gazette.

THE BOOK OF OLD-FASHIONED FLOWERS. By Harry Roberts, Author of "The Chronicle of a Cornish Garden."

"All who wish for a real old-fashioned garden should certainly study this most excellent and practical book, "-Bookman.

THE BOOK OF BULBS. By S. ARNotT, F.R.H.S., of Carsethorne, near Dumfries. Together with an introductory chapter on the Botany of Bulbs by the Editor.

"Skilled and instructive. It notably enriches the series in which it appears."-Scotsman.

THE BOOK OF THE APPLE. By H. H. Thomas, Assistant Editor of The Garden, late of the Royal Gardens, Windsor. Together with chapters by the Editor on the History and Cooking of the Apple and the Preparation of Cider.

"This is a most useful volume, which every grower, whether for his own use or for the market, should consult." - Spectator.

THE BOOK OF VEGETABLES. By GeORge Wythes, V.M.H., Head Gardener to the Duke of Northumberland. Together with chapters on the History and Cookery of Vegetables by the Editor.

"Thoroughly practical. The book can be highly recommended." Morning Post.

THE BOOK OF ORCHIDS. By W. H. WHITE, F.R.H.S., Orchid Grower to Sir Trevor Lawrence, President of the Royal Horticultural Society.

"There are few writers so well qualified to write with authority upon these flowers." - Scotsman.

THE BOOK OF THE STRAWBERRY. With chapters on the Raspberry, Blackberry, Loganberry, Japanese Wineberry, and Allied Fruits. By EDwin Becketr, F.R.H.S.

"Mr Beckett deals with his subject in a thorough practical manner . . and fully maintains the general excellence shown in the previous volumes of this series."-Morning Post.

THE BOOK OF CLIMBING PLANTS. By S. ARNOTT, F.R.H.S., Author of "The Book of Bulbs."

"This is a concise, practical, and well-informed exposition of skilled knowledge as to the training of creepers, \&c."-Scotsman. 
THE BOOK OF PEARS AND PLUMS.

By the Rev. E. BARTRUM, D.D., F.R.H.S.

"The writer knows as much about the growing of Pears and Plums as Dean Hole knows about the cultivation of Roses." -Scotsman.

THE BOOK OF HERBS. By LADY ROSAlini) NoRTHCOTE. THE BOOK OF THE WILD GARDEN.

By S. W. FitzHERBERT.

THE BOOK OF THE HONEY-BEE.

By Charles Harrison.

THE BOOK OF SHRUBS. By GeORGE Gordon, V.M.H.,

Editor of The Gardener's Magazine.

A special feature of this book lies in the distinction which it makes between shrubs and trees peculiarly suited to garden cultivation, and those appropriate to the park and woodland. The author desires to encourage the culture of shrubs in gardens, and indicates those most suitable for various purposes and situations.

THE BOOK OF THE DAFFODIL.

By the Rev. S. Eugene Bourne.

The author supplies valuable information on the cultivation of daffodils gained by the results of his own personal experience.

THE BOOK OF THE LILY. By W. GOLDRING.

A description of, and a practical guide to, the cultivation of all the lilies usually to be found in British gardens.

THE BOOK OF TOPIARY.

and W. Gibson, Head Gardener at Levens Hall.

A textbook of the topiary art, together with some account and famous examples of the application of that art.

THE BOOK OF TOWN AND WINDOW GARDENING. By Mrs F. A. Bardswell.

THE BOOK OF RARER VEGETABLES. By GEORGE Wythes, V.M.H., Head Gardener to the Duke of Northumberland, and HARRY ROBERTS.

THE BOOK OF THE IRIS. By R. IRWIN LYNCH, A.L.S., Curator of the Botanic Gardens, Cambridge.

THE BOOK OF GARDEN FURNITURE.

By Charles Thonger.

THE BOOK OF THE CARNATION.

By C. P. Brotherston and Martin R. SMith.

THE BOOK OF TIHE SCENTED GARDEN.

By F. W. BurbidGe, M.A., V.M.H., F.R.H.S., London.

THE BOOK OF GARDEN DESIGN.

By Charles Thonger.

THE BOOK OF THE WINTER GARDEN.

By D. S. Fish, of the Royal Botanic Gardens, Edinburgh.

THE BOOK OF MARKET GARDENING. By R. LEWIS CASTLE, Author of "Commercial Fruit Growing, and Grading and Packing of Fruits and Vegetables," \&c.

THE BOOK OF ROCK AND WATER GARDENS.

By Charles Thonger, Author of "The Book of Garden Design."

A handbook to rock, wall, and water gardening, with a detailed account of the culture of Alpine plants.

THE BOOK OF THE CHRYSANTHEMUM. By PERCY S. Follwill, Head Gardener at Drumpellier Gardens, Coatbridge.

THE BOOK OF FRUIT BOTTLING.

By Edith Bradley and May Crooke.

THE BOOK OF GARDEN PESTS AND PLANT Diseases. By R. Hooper Pearson, F.R.H.S. 
THERE IS

BEAUTY AND FRAGRANCE

\section{IN EVERY \\ GREENHOUSE}

\section{WHERE}

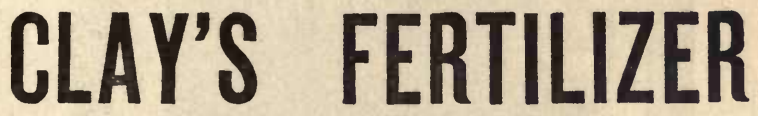

IS USED. IT PRODUCES

FLOWERS AND FOLIAGE

in profusion, and in the highest perfection.

It is SAFE, QUICK, LASTING, and UNSURPASSED for ALL HORTICULTURAL PURPOSES.

It is used by the Leading Growers, Government and Local

Authorities, and by Horticulturists throughout the World.

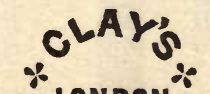

$\rightarrow$ LONDON

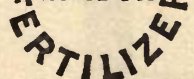

TRADE MARK.

Sold everywhere in 6d. and 16. Tins; and Sealed Bage $\rightarrow$ lbs., 2s. 6d.; 14 lbs., 48. 6d.; 28 lbs., 78. 6d.; 56 lbs., 12s. 6d.; II2 lbs., 20 .

Or direct from the Works, Carriage Paid in the United Kingdom for Cash with Order (except 6d. Tins).

Every Genuine Tin, Bag, and seal bears the TRADE MARK.

\section{Full Directions for use appear in CLAY'S SUCCESSFUL GARDENING.}

Containing Instructions upon all Horticultural Topics by Eminent Writers. Illustrated, Enlarged, and Revised. Bound in Cloth, 9d. post free, or of Seedsmen.

Write for full Price List of Manures, Chemicals, and Sundries.

OIAL \& SON,

Manure Manufacturers, Bone Crushers, Etc. STRATFORD, LONDON, E. 


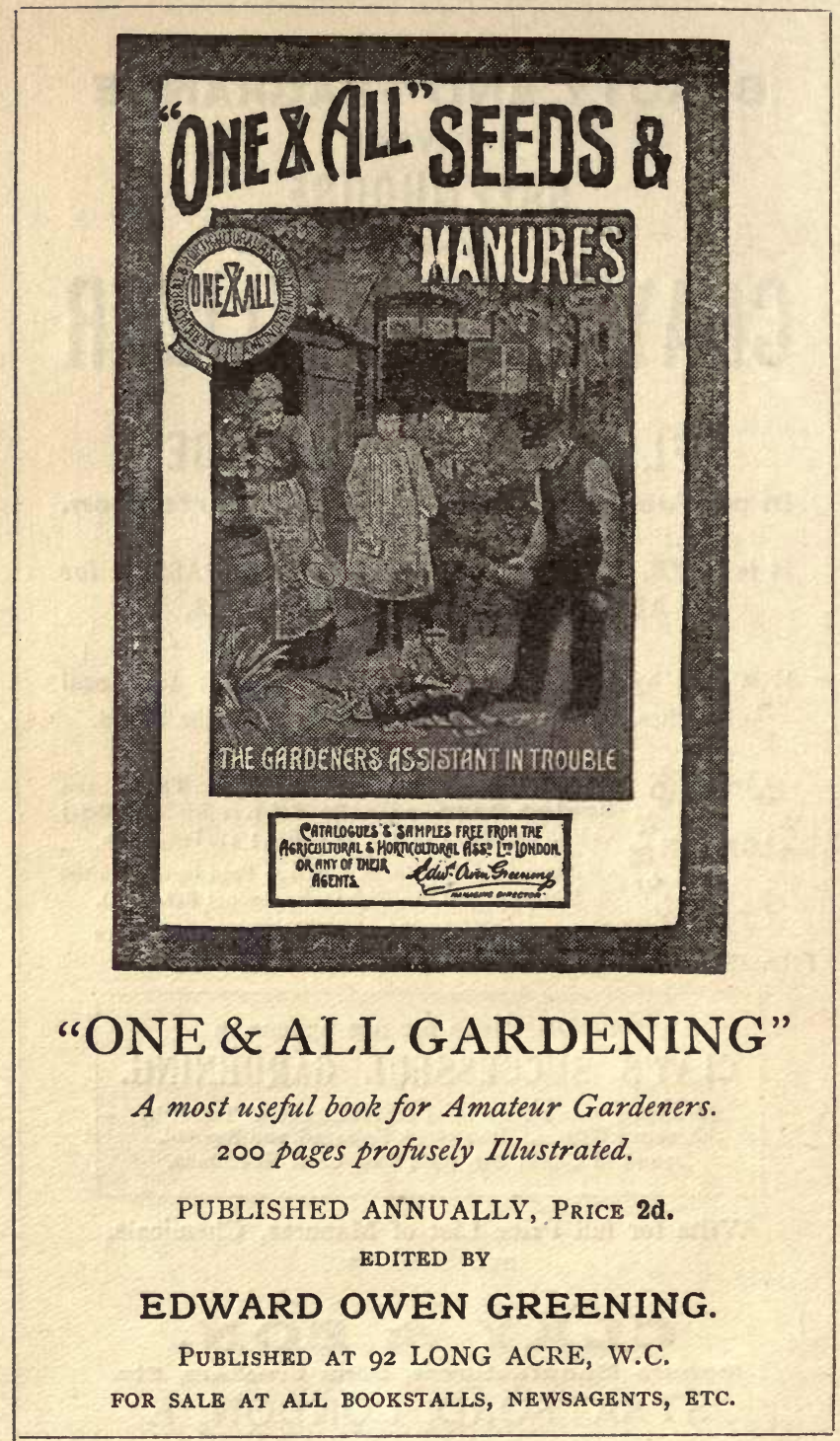



THIS BOOK IS DUE ON THE LAST DATE STAMPED BELOW

\section{AN INITIAL FINE OF 25 CENTS} WILL BE ASSESSED FOR FAILURE TO RETURN THIS BOOK ON THE DATE DUE. THE PENALTY WILL INCREASE TO 50 CENTS ON THE FOURTH DAY AND TO \$1.00 ON THE SEVENTH DAY OVERDUE.

\begin{tabular}{|c|c|}
\hline \multirow{2}{*}{ AUG 111936} & DEC 31978 \\
\hline & AEC. CIR. DEC 121978 \\
\hline \multirow{2}{*}{ MAY 311940} & NOV 231980 \\
\hline & \\
\hline \multirow{3}{*}{ 18jan'57Kf } & RECEIVED BY \\
\hline & NOV 111580 \\
\hline & CIRCULATION DEPT. \\
\hline \multicolumn{2}{|l|}{ RECD LD } \\
\hline \multicolumn{2}{|l|}{ JAN 251957} \\
\hline \multicolumn{2}{|l|}{ NOV 12197368} \\
\hline \multicolumn{2}{|c|}{ RECODLO NOVP } \\
\hline \multicolumn{2}{|c|}{ Novedelenes } \\
\hline \multicolumn{2}{|l|}{ BEP PIS OCF 2979} \\
\hline & \\
\hline & \\
\hline & LD 21-100m-8, 34 \\
\hline
\end{tabular}


YB 48585
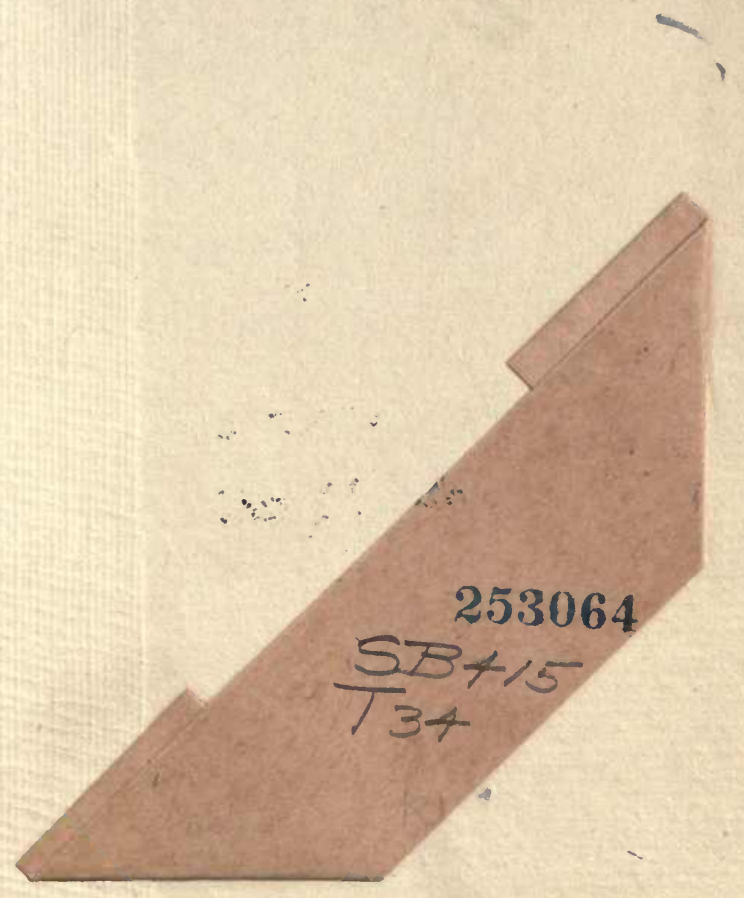
